WALDEN

UNIVERSITY

A higher degree. $A$ higher purpose.

Walden University ScholarWorks

2018

\title{
Small Business Marketing Strategies for Physical Therapy Practice Owners
}

Matthew Lane Daugherty

Walden University

Follow this and additional works at: https://scholarworks.waldenu.edu/dissertations

Part of the Advertising and Promotion Management Commons, Marketing Commons, Occupational Therapy Commons, and the Physical Therapy Commons

This Dissertation is brought to you for free and open access by the Walden Dissertations and Doctoral Studies Collection at ScholarWorks. It has been accepted for inclusion in Walden Dissertations and Doctoral Studies by an authorized administrator of ScholarWorks. For more information, please contact ScholarWorks@waldenu.edu. 


\title{
Walden University
}

\author{
College of Management and Technology
}

This is to certify that the doctoral study by

\author{
Matthew Lane Daugherty
}

has been found to be complete and satisfactory in all respects, and that any and all revisions required by the review committee have been made.

\begin{abstract}
Review Committee
Dr. Jamie Klein, Committee Chairperson, Doctor of Business Administration Faculty Dr. Rocky Dwyer, Committee Member, Doctor of Business Administration Faculty Dr. Mohamad Hammoud, University Reviewer, Doctor of Business Administration Faculty
\end{abstract}

Chief Academic Officer Eric Riedel, Ph.D.

Walden University 2018 


\begin{abstract}
Small Business Marketing Strategies for Physical Therapy Practice Owners

by

Matthew Lane Daugherty
\end{abstract}

MOT, University of St. Augustine, 2006

BS, University of Akron, 2003

\author{
Doctoral Study Submitted in Partial Fulfillment \\ of the Requirements for the Degree of \\ Doctor of Business Administration
}

Walden University

December 2018 


\begin{abstract}
The United States economy depends on small businesses, which represent $99 \%$ of all businesses in the United States, yet approximately $50 \%$ of small businesses cease operations in the first 5 years. The purpose of this multiple case study was to explore the marketing strategies used by owners of small businesses to develop and maintain their organization through the initial 5 years of business operation. The population included 5 physical therapy business owners in northeastern Florida who had sustained their business for a minimum of 5 years. The conceptual framework for this study was the brand equity model, and data were collected through semistructured interviews, online company marketing materials, and archival company documents. Yin's 5-step analysis guided the data analysis process: (a) collecting data, (b) grouping data into codes (c) grouping data into themes (d) assessing the themes, and (e) developing conclusions. Member checking, transcript review, and triangulation were used to validate the study data. The 5 study themes were brand awareness, relationship marketing, perceived quality, social media and online marketing, and word-of-mouth marketing. The implications of this study for positive social change include the potential for economic growth in the physical therapy practice market, as well as improved patient access to physical therapy services through a greater number of physical therapy practices.
\end{abstract}


Small Business Marketing Strategies for Physical Therapy Practice Owners by

Matthew Lane Daugherty

MOT, University of St. Augustine, 2006

BS, University of Akron, 2003

Doctoral Study Submitted in Partial Fulfillment

of the Requirements for the Degree of

Doctor of Business Administration

Walden University

December 2018 


\section{Dedication}

This doctoral study is dedicated to my grandfather, Robert Daugherty. 


\section{Acknowledgments}

With sincere gratitude I would like to thank Dr. Jaime Klein, Dr. Rocky Dwyer, and Dr. Mohamad S. Hammoud for their expertise, guidance, and support in this endeavor. Your mentorship made me a better scholar, writer, and, researcher. In addition, I would like to thank Dr. Susan Davis and Mr. Fred Walker for your contributions to the Doctor of Business Administration program. Lastly, I would like to thank my family for their loving support and patience throughout this endeavor. 


\section{Table of Contents}

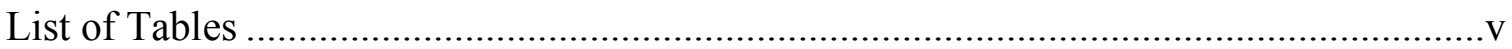

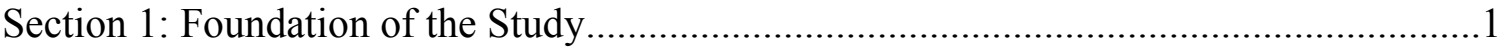

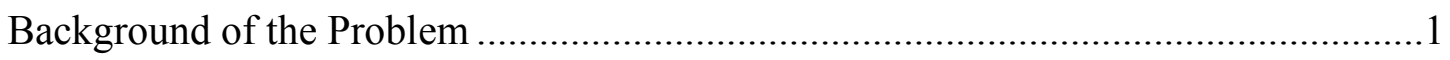

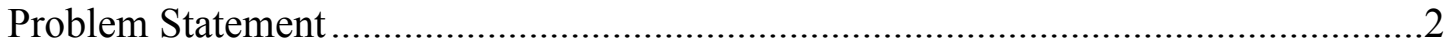

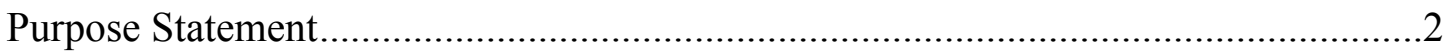

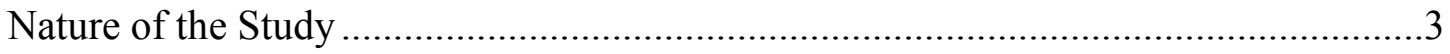

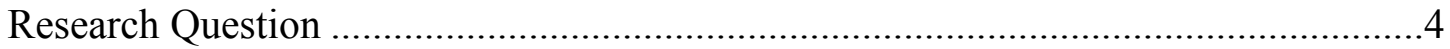

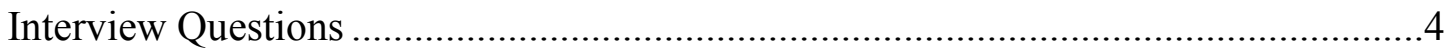

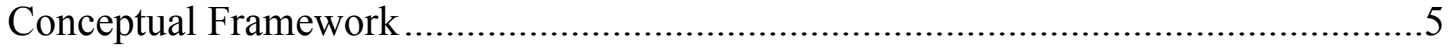

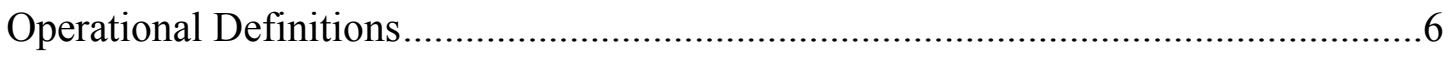

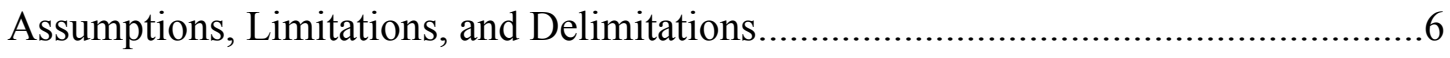

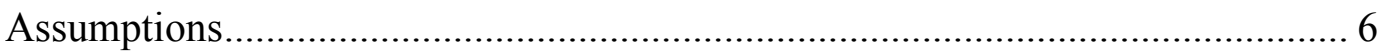

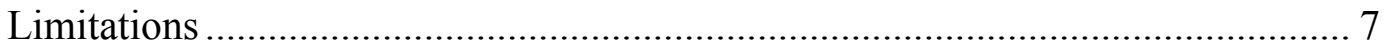

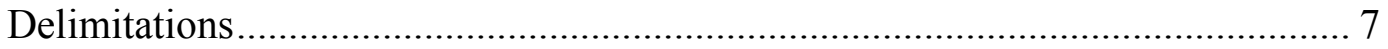

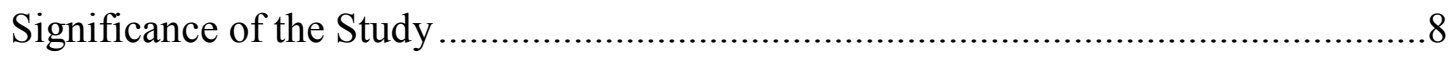

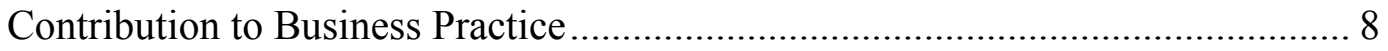

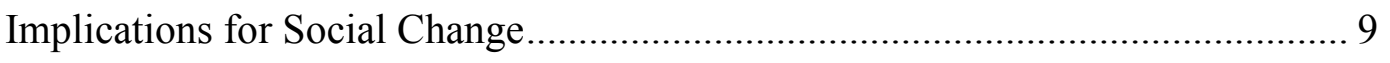

A Review of the Professional and Academic Literature..........................................

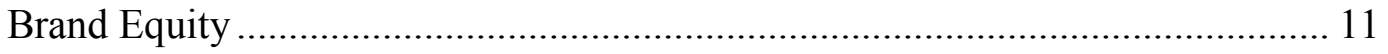

Brand Awareness ..................................................................................... 13 


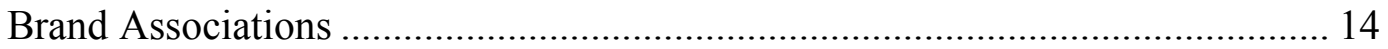

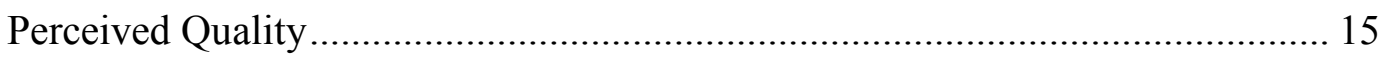

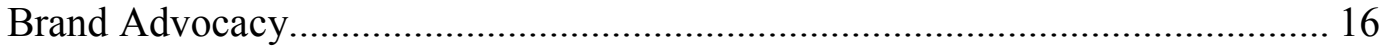

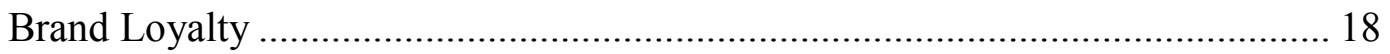

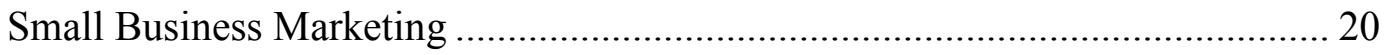

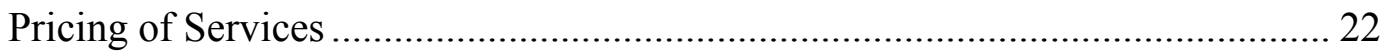

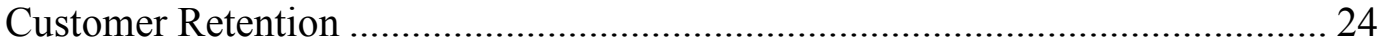

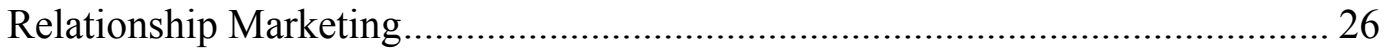

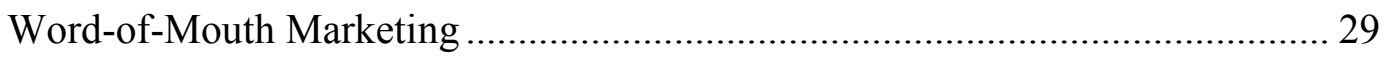

Social Media Marketing.................................................................................. 31

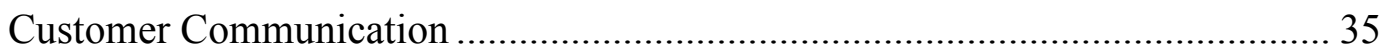

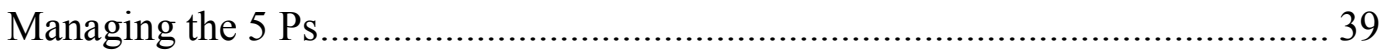

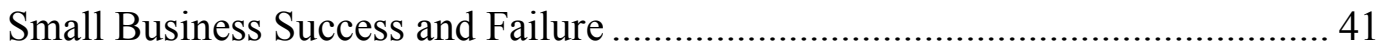

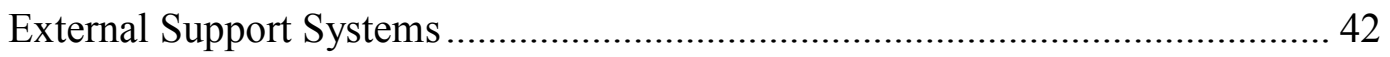

Health Care Marketing Plans ............................................................................. 43

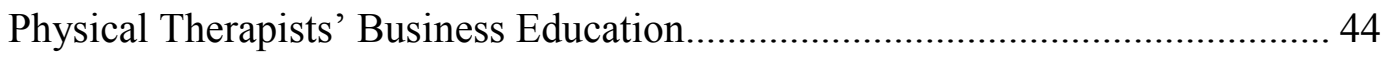

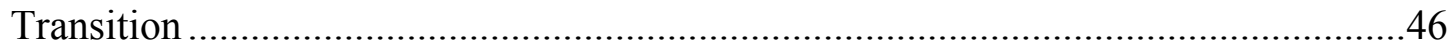

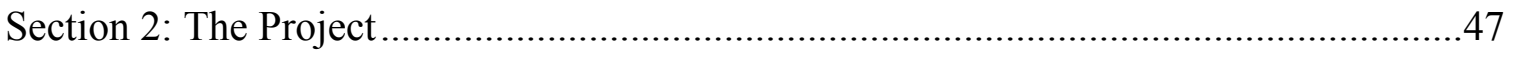

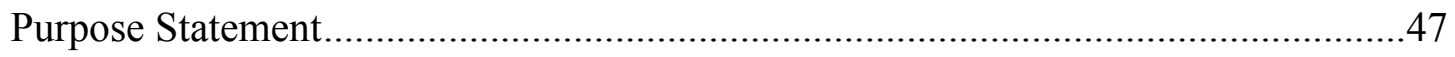

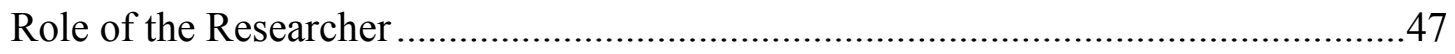

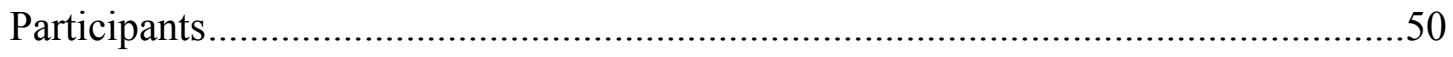




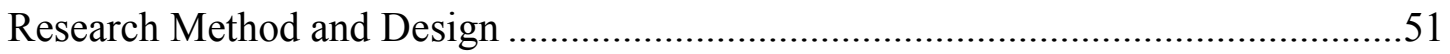

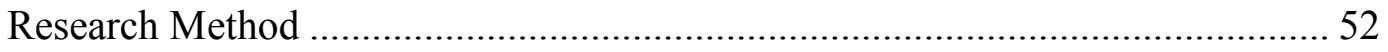

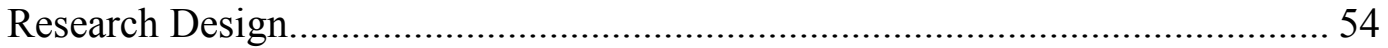

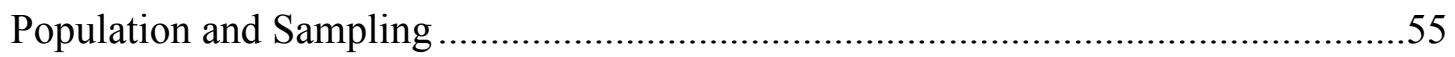

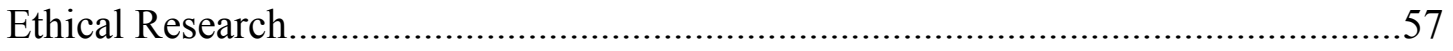

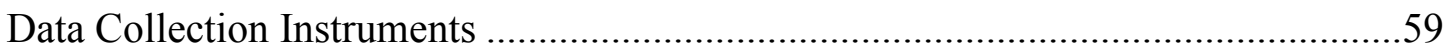

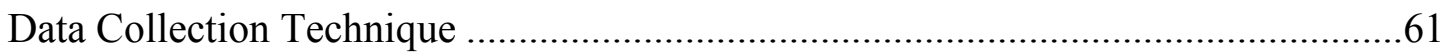

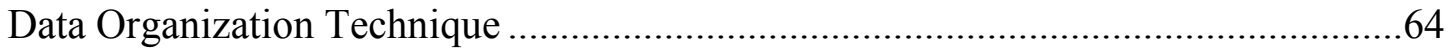

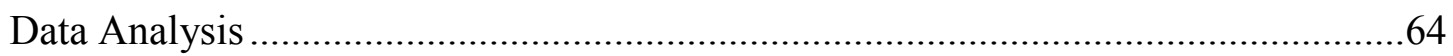

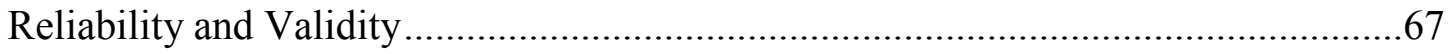

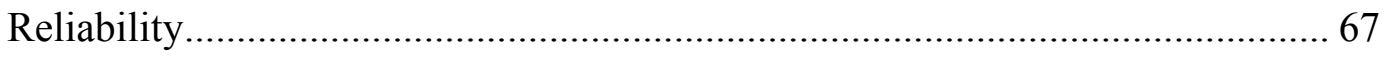

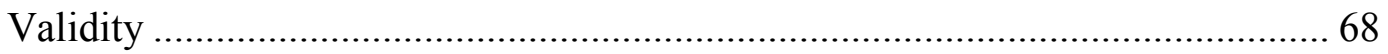

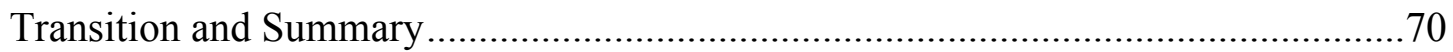

Section 3: Application to Professional Practice and Implications for Change ...................71

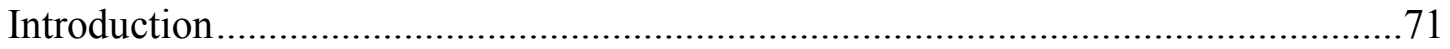

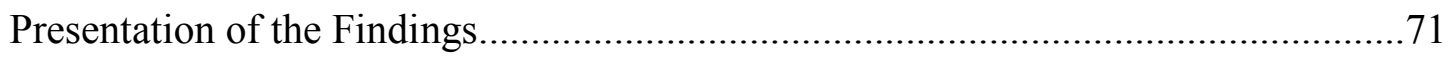

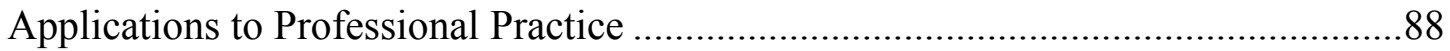

Implications for Social Change............................................................................90

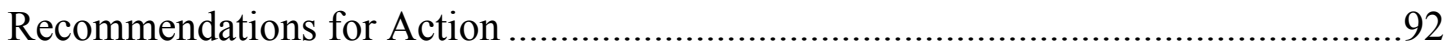

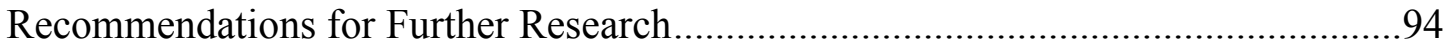

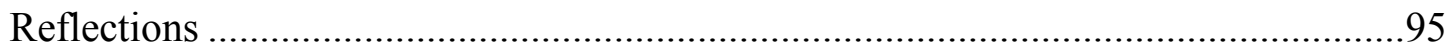




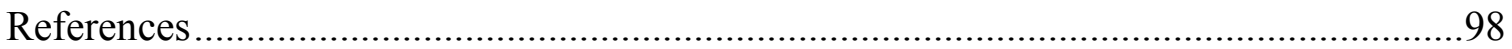

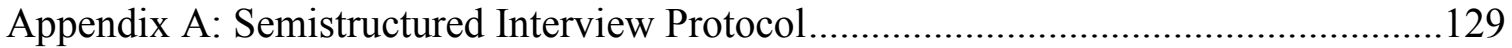

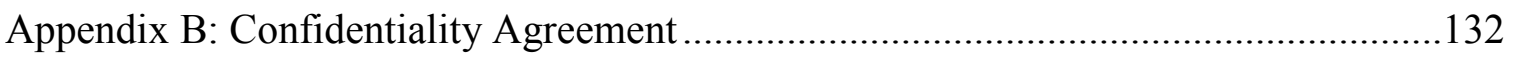




\section{List of Tables}

Table 1. Coding of Participants' Responses Related to Themes .................................. 74

Table 2. Number of Marketed Physical Therapy Specializations ................................. 82

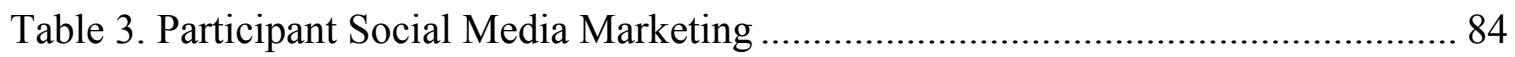


Section 1: Foundation of the Study

Small businesses are an essential part of the United States economy. Small business owners employ $99 \%$ of all workers in the United States, yet their businesses often struggle to survive the initial 5 years of operation (U.S. Small Business Administration [SBA], 2014). Although small businesses cover many sectors, small health care businesses such as physical therapy practices are in particularly high demand (Landry et al., 2016). To ensure success and survival of their business, small physical therapy practice owners must develop effective marketing strategies (Bennett, 2016). The purpose of this qualitative study was to explore the marketing strategies that small physical therapy practice owners use to sustain their business for the initial 5 years. In this section, I covered the foundation of the study including core components of the background of the problem, the problem statement, the purpose statement, the nature of the study, the research question, the conceptual framework, and operational definitions. I also classified the assumptions, limitations, delimitations, and significance of the study, and included a literature review and transition to the next section.

\section{Background of the Problem}

The U.S. economy is significantly reliant on small businesses. More than 28 million small business owners employed $99 \%$ of all United States workers and provided $63 \%$ of new jobs over a recent 10 -year period (SBA, 2015). Small business activity can stimulate a competitive and entrepreneurial environment within communities, which in turn enhances productivity growth and positive social change (Deller \& Conroy, 2016). 
Yet researchers have inadequately addressed small medical practices, including physical therapy practices (DeAngelis, 2014; Sahni, Rana, \& Talwar, 2015).

Specifically, physical therapists are self-directed health care practitioners with expanding scopes of practice used to serve diverse patient populations. Because of the aging patient population, the strong demand for physical therapists is expected to continue to increase (Sloan, 2015). Physical therapy business owners need to share their successful marketing strategies to foster physical therapy practice growth and to serve the aging United States population better.

\section{Problem Statement}

More than $50 \%$ of small business firms in the United States fail within the first 5 years of operation (Hayes, Chawla, \& Kathawala, 2015). In 2014, 28.4 million small businesses constituted $99 \%$ of the total U.S. workforce, making small business firms essential to the economy (SBA, 2015). The general business problem is that small business owners who lack marketing strategies risk profit loss and business closure. The specific business problem is that some physical therapy practice owners lack marketing strategies to sustain their business beyond 5 years of operation.

\section{Purpose Statement}

The purpose of this qualitative multiple case study was to explore marketing strategies physical therapy practice owners use to sustain their businesses beyond 5 years of operation. The targeted population for this study comprised five owners of five physical therapy practices in northeast Florida who have successfully implemented 
marketing strategies to sustain their business beyond 5 years of operation. The implication for positive social change includes the potential to increase physical therapy services to those in need of rehabilitation in northeast Florida.

\section{Nature of the Study}

The three most common research methods are qualitative, quantitative and mixed (Yin, 2014). Qualitative researchers seek to explore the what and why of a phenomenon (J. Park \& Park, 2016). By serving as the key instrument and analyzing multiple sources of data, including archival data, a qualitative researcher can use multiple research tools to add a personal voice by interviewing participants in their natural environment (Yin, 2014). Quantitative researchers test hypotheses to examine variables' relationships and differences in an impersonal voice (Graue, 2015). The quantitative method was not appropriate for this study. Mixed-method research is appropriate when the researcher combines both quantitative and qualitative methodologies (Venkatesh, Brown, \& Sullivan, 2016; Yin, 2014). I did not use any quantitative methods in this study, so the mixed-method approach is not applicable. Because the study was designed to explore marketing strategies that physical therapy business owners use to sustain their business, the qualitative method was most appropriate for this study.

Qualitative researchers use four research designs: (a) phenomenological, (b) ethnographic, (c) narrative, and (d) formal case study (Yin, 2014). Researchers use a phenom-enological design to identify the meanings of human experiences as related to a specific phenomenon (Yin, 2014). Ethnographic researchers explore shared patterns of a 
group to better understand that group's culture (Hammersley, 2016). Narrative researchers seek to explore the lives of individuals and compare the views of the individuals to the narrative researchers' own (Levitt, 2016). Case study research is a viable option researchers can use to gather emerging ideas from multiple sources (Yin, 2014). Additionally, using a multiple case study design enables researchers to use inductive data analysis (Park \& Park, 2016). I selected a qualitative case study design to explore marketing strategies physical therapy small business owners use to sustain their business for at least 5 years.

\section{Research Question}

What marketing strategies do owners of small physical therapy practices use to sustain their businesses beyond 5 years of operation?

\section{Interview Questions}

1. What marketing strategies have you used to sustain your business?

2. What marketing strategies do you use to retain current patients?

3. What marketing strategies do you use to gain new patients?

4. What are your current primary barriers to using marketing strategies?

5. How have you overcome these barriers?

6. How have your marketing strategies evolved over the past 5 years?

7. How do you market your brand for perceived quality of service?

8. How do you measure the effectiveness of your marketing strategies? 
9. What other information can you provide about marketing strategies of your business that we have not already discussed?

\section{Conceptual Framework}

Aaker (1991) developed the brand equity model, which consists of five key constructs categorized as either brand assets or liabilities: (a) brand loyalty, (b) brand awareness, (c) perceived quality, (d) brand associations, and (e) other proprietary brand assets. Aaker proposed the business owner can apply the tenets of the brand equity model as either additions or subtractions of value to the business. For example, if customers have brand loyalty, the business owner will save money by retaining loyal customers versus winning new ones (Davcik, Vinhas da Silva, \& Hair, 2015). In the same example, brand loyalty is an addition to the value of the business. Although certain metrics of brand equity can be formally measured, financial performance measures are not inclusive of the intangible brand assets such as brand associations.

Building upon Aaker's (1991) brand equity model, Davcik et al. (2015) published a conceptual framework dividing the brand equity model into either a consumer or a company focus. Davcik et al. argued the three business domains in creating brand equity are financial performance, marketing assets, and stakeholder value. I expected the brand equity model to be relevant to the success of physical therapy small business owners. More specifically, the marketing strategies of physical therapy small business owners either add or subtract value to the brand. The current value of the physical therapy brand 
affects firm sustainability. I used Aaker's brand equity model as the foundation for the literature review and explored its actual relevance in the discussion of findings.

\section{Operational Definitions}

Brand equity: The perceived value of a brand from the perspective of the consumer (Aaker, 1991).

$S B A$ : An independent agency of the federal government that aids, counsels, assists, and protects the interests of small businesses (SBA, 2017).

Social media marketing: Advertising through the medium of social media such as Facebook, Instagram, and Twitter (Holt, 2016).

\section{Assumptions, Limitations, and Delimitations}

\section{Assumptions}

According to Yin (2014), certain assumptions, limitations, and delimitations are present in all case study research endeavors. Assumptions are the ideas and concepts a researcher believes to be fact without objective proof (Helmich, Boerebach, \& Arah, 2015). Assumptions carry risks and inherently influence not only study design, but also research outcomes for qualitative studies. In this qualitative study, I made several assumptions related to study design and methodology.

First, I assumed the qualitative case study design with semistructured interviews would be the best method to collect information about marketing strategies for physical therapy small business owners. A second assumption was participants would be open and honest with their answers to my interview questions, with minimal bias. Third, I assumed 
the participants would have adequate experience with marketing in their business to provide enough information for me to address the central research question.

\section{Limitations}

A limitation is a restriction out of the researcher's control because of the nature of the project and can be a source of methodology weakness (Levitt, 2016). A researcher should carefully consider study limitations when designing qualitative research studies (Chowdhury, 2015). Other limitations include the time of data gathering and participation bias. Because the outcomes of this study are based on data from a specific period, the results should be considered applicable only to the time considered for this study and not considered an accurate representation of successful small business marketing strategies from previous or later timeframes. Lastly, participation bias may occur during the interviews.

\section{Delimitations}

Yin (2014) proposed that the delimitations are the boundaries a researcher sets for the scale of the study. These limitations are necessary to ensure that research can be completed without becoming impossibly large in scale or scope. The first delimitation was my selection of convenience rather than random sampling. This study was limited to small physical therapy practice owners whom I selected. This convenience sampling limitation affects the external validity of the outcomes and presents a potential researcher bias to this study. I also delimited the study to physical therapy practice small business owners who have been in business for 5 years or more in northeast Florida. Any physical 
therapy practice owners who did not own a business with fewer than 500 employees or whose practice was not located in northeastern Florida were excluded from the study.

\section{Significance of the Study}

This study is of value to the success of small business owners, many of whom face failure in their first 5 years. Despite the economic influence of small businesses on the economy of northeast Florida, the marketing strategies that contribute to the success of small business owners of physical therapy practices are largely unknown (SBA, 2016). Firms with fewer than 100 employees represent the largest share of small business employment, and in 2015, Florida small business owners employed 3.1 million people (SBA, 2016). The implications for business practice include the potential to aid small physical therapy business owners in sustaining their business through the first 5 years of operation.

\section{Contribution to Business Practice}

Successful physical therapy business owners provide quality physical therapy care for the aging U.S. population. Back pain and arthritis are the most common and costly conditions within the United States, affecting more than 100 million individuals and costing greater than $\$ 200$ billion per year (Ma, Chan, \& Carruthers, 2014). Of all common rehabilitation diagnoses, back pain and arthritis have the greatest influence on the health care system. Physical therapists can help patients manage painful musculoskeletal conditions such as back pain and arthritis (Ladeira, Cheng, \& da Silva, 2017). Demand for physical therapy practices has increased because of the aging 
population in the United States requiring rehabilitation services provided by physical therapists (Landry et al., 2016). The findings of this study address the marketing strategies that small business owners of successful physical therapy practices use to sustain their business in northeast Florida. Local small physical therapy practice owners will benefit from acquiring marketing strategies to help them retain current patients and attract new patients. These findings will also help local physical therapy practice owners learn effective marketing strategies to sustain their business, therefore, improving access to local physical therapy services.

\section{Implications for Social Change}

Successful physical therapy small business owners can contribute to the improvement of small businesses practice and positive social change. Physical therapy small business owners play an important role in the health of the U.S. economy and citizens. Sharing this study's results with the physical therapy private practice community may help some small physical therapy business owners sustain their business past the initial 5 years of operation. More successful physical therapy practices can help physical therapists provide care for the increasing health care service demand of society, therefore, promoting healthy cultures and stimulating the local economy.

\section{A Review of the Professional and Academic Literature}

The purpose of this literature review is to summarize, compare, and contrast sources that relate to the research topic of small business marketing strategies through the concept of brand equity. This section begins with an overview of literature focusing on 
the conceptual framework of brand equity, perceived quality, brand advocacy, brand loyalty, small business marketing, word-of-mouth marketing, social media marketing, pricing of services, customer retention, managing the 5 Ps, and physical therapy business education. For this study, the Walden University Online Library provided the primary databases to search business and management literature including. Business Source Complete, ABI/Inform, and Advanced Google Scholar. I used the following keywords in my searches: small business and success, small business and failure, small business marketing, small business and marketing strategies, marketing plan, small business and physical therapy, small business strategies, physical therapy clinic, and physical therapy practices.

Peer-reviewed articles compromise much of this literature review. The additional references are government sources or seminal works. One limitation of this literature review stems from a lack of research devoted specifically to physical therapy business enterprises. More specifically, I did not find any studies related to physical therapy business practices in northeast Florida. Hence, more research is necessary on physical therapy practice marketing strategies to shed light on these strategies to help future business owners provide physical therapy care to those in need. I used 101 sources in the literature review of this study with 90 peer-reviewed articles published in the last 5 years. For the literature review $89 \%$ of sources are peer-reviewed and published in the last 5 years. I used a total of 195 resources with 188 peer-reviewed articles and 173 peerreviewed articles published in the last 5 years. In total $89 \%$ of the total articles are peer- 
reviewed and published within 5 years of Walden's chief academic officer expected approval.

\section{Brand Equity}

Aaker (1991) developed the brand equity model, which consists of five brand assets and liabilities: brand loyalty, brand awareness, perceived quality, brand associations, and other proprietary brand assets. Brand equity has no single focus but is split into three constructs. Brand equity and consumer equity are related to the financial perspective of the business and the customer-based perspective (Girard, Trapp, Pinar, Gulsoy, \& Boyt, 2017). The third focus of perspective is the combination vantage point of both the business and the consumer. In two thirds of the potential perspectives of brand equity, customers are major stakeholders and can make a significant influence on the direction of the marketing strategies. A researcher can view effective marketing strategies through the lens of the brand equity model but must also consider the perceptive of the consumer (Datta, Ailawadi, \& van Heerde, 2017; Datta, Foubert, \& Van Heerde, 2015). A consumer-based perspective of the brand equity model is called consumer-based brand equity (CBBE).

The value of a brand is difficult for marketing professionals to estimate and measure due to its intangible nature. When marketers or small business owners use CBBE, they measure the consumers' emotions toward a brand through research activities. The importance of research on building brand equity is particluraly emphasized within consumer driven marketplaces (Šerić, Gil-Saura, \& Mikulić, 2017). However, the CBBE 
is more subjective than a financial-based brand equity (FBBE) model and therefore requires different constructs and measures such as Yong \& Rubicam's Brand Asset Valuator and YouGov's Brand Index (Datta et al., 2017). Šerić et al. (2017) proposed a strong association with brand equity and the concepts of marketing strategy and competitive advantage from the FBBE perspective. The relationship between $\mathrm{CBBE}$ and FBBE is worth further exploration.

Although marketing researchers have emphasized the importance of brand equity, an accepted estimation model of the relationship between CBBE and FBBE is not uniformly accepted (Çifci et al., 2016; M. O. R. de Oliveira, Silveira, \& Luce, 2015). Other researchers argued that brand equity researchers have missed the complexity of measuring the phenomenon of $\mathrm{CBBE}$ and instead treated $\mathrm{CBBE}$ as a linear construct (Chatzipanagiotou, Veloutsou, \& Christodoulides, 2016). These authors discredited previous research of CBBE and instead use complex theory and fuzzy qualitative comparative analysis to endorse a framework of CBBE as both dynamic and sequential (Chatzipanagiotou et al., 2016). The theory devised by Chatzipanagiotou et al. (2016) consisted of three interelated concept blocks: brand builiding, brand understanding, and brand relationships. This theory allows brand managers to anticipate the results of their marketing efforts (Chatzipanagiotou et al., 2016) as opposed to a static construct linear in nature without predictive qualities (Liu, Wong, Tseng, Chang, \& Phau, 2017).

Aaker (1991) proposed the business owner can apply the tenets of the brand equity model as either additions or subtractions of value to the business. For example, if 
customers have brand loyalty, the business owner will save money by hanging on to loyal customers versus winning new customer (Davcik et al., 2015). In the example above, brand loyalty is an addition to the value of the business. Although certain metrics of brand equity can be formally measured, financial performance measures are not inclusive of the intangible brand assets, such as brand awareness and associations.

\section{Brand Awareness}

Brand awareness is the ability of a potential consumer to recall that a brand is a member of its market category (Aaker, 1991; Girard et al., 2017; Kim \& Kim, 2016). Brand awareness is the continuum ranging from consumer uncertainty to the belief that it is the only brand in the market share. Brand awareness is at its core the amount of brand knowledge that a consumer possesses. Brand knowledge is built by focusing on the emotional connection the consumer has with the brand. The global appeal has a stronger relationship with brand knowledge components in countries with low gross domestic product (Zarantonello, Schmitt, \& Jedidi, 2014).

Brand awareness is not just limited to social media and television venues. Nowadays, brand managers are wise to insert advertising into video games if their brands are already familiar. Martí-Parreño, Bermejo-Berros, and Aldás-Manzano (2017) found that consumers recalled familiar brands placed in video games better than they recalled unfamiliar brands. However, repetition of a brand placement within video games did not affect brand recognition. Therefore, both familiar and unfamiliar brands to the consumer will benefit from the effective repetition of brand placement. 


\section{Brand Associations}

Remarkably, the way a business owner's brand makes a customer feel can affect brand equity (Aaker, 1991; Milan, Eberle, \& Bebber, 2015). The brand association has substantial value to brand managers. Aaker (1991) defined brand association as anything linked in memory to a brand, including emotion. For example, a customer could link McDonald's brand to its key marketing character Ronald McDonald and the feeling of having fun. This association is driven by what consumers know about the brand. Chen, Nelson, and Hsu (2015) called humanlike characteristics associated with brands brand personality. A consumer uses the brand personality to humanize the brand associations to create feelings, differentiate the brand's position in the marketplace, and even help retrieve memory information (Aaker, 1991; Chen et al., 2015). Brand managers strive to create intentional brand associations within the minds of their customers by using a process called anchoring.

Brand anchoring is a metaphor for the associations a customer makes to a brand by way of memory links considered chains to the anchor, which is the brand (Aaker, 1991; Esch, Schmitt, Redler, \& Langner, 2009; Hviid \& Shaffer, 2012). Anchoring is a form of consumer bias but can work to a small business owner's advantage. The anchoring associations of Toyota Motor Corporation might include reliable vehicles, family cars, quality, and resale value (Jayamaha, Wagner, Grigg, Campbell-Allen, \& Harvie, 2014). These are all positive anchors that help foster positive brand associations. However, the anchors are not always positive and could cause the consumer to have 
detrimental associations with the brand. Toyota executives have had to earn these positive brand associations back over the past 10 years since surviving a product harm crisis for unintentional accelerating vehicles. During this time the brand association chains may have included dangerous, dishonesty, faulty electronics, and product harm (Tennert, 2014). These associations are not permanently tied to the anchor brand, and the stronger the reputation of the brand the easier these negative associations are to break.

Brand managers exhibit significant effort to create intentional brand associations in the customer's mind. They do this to capitalize on marketing researchers' view that intended brand associations are a driver of both customer response and brand equity (Koll \& von Wallpach, 2014). A match between intended and actual brand association leads to positive customer response. Positive customer response to two brand association can be manifested in a variety of ways to provide value for the brand. Positive customer response includes behaviors such as customer purchase decisions and their brand loyalty.

\section{Perceived Quality}

Perceived quality is the customer's perception of the overall excellence of a product or service. The perceived quality is different from related concepts such as objective quality, product-based quality, and manufacturing quality. The customer's assessment is given in consideration of the intended purpose of the product or service and comparison to alternatives and is subjective (Aaker, 1991; Vera, 2015). Perceived quality is a concept Aaker (1991) proposed to include the following value variables: a reason to buy, differentiate/position, price, channel member interest, and extensions. When a 
consumer feels the quality of a product or service is high, he or she now has a reason to buy. In the service industry, younger consumers may judge initial service quality as lower because of their decreased perception of service quality as a whole (Yaya, Fortià, Canals, \& Marimon, 2015). In the retail product market, perceived quality and brand awareness are markers for brand performance (Girard et al., 2017). Perceived quality can encourage perceived value and cause a customer to pay a higher price for the product or service (Vera, 2015). If the customer is willing to judge a higher perceived value of a product or service, the marketing strategies may be more effective.

The perceived quality affects not only the customer's disposition to pay a higher price but is pivotal for a high cost-to-performance service strategy to work. Ultimately, perceived quality is the foundation of the customer's disposition to pay a higher price but not the only variable (Thi Minh Pham, Nga Do, \& Minh Phung, 2016; Vera, 2015). When a customer thinks of a brand, the associations that come to the customer's mind can affect the pricing of the service and the customer's willingness to purchase.

\section{Brand Advocacy}

Brand advocacy is when a customer's experience creates positive attitudes and emotions toward a business that manifests in a recommendation of that service or product to other potential customers. Brand advocacy is the highest level of customer loyalty and is directly linked to the most successful form of marketing, word-of-mouth (WOM) (Keller, 2007; R. A. King, Racherla, \& Bush, 2014). The customer engages in brand advocacy as soon as he or she spreads any WOM marketing, most commonly via social 
media. With the vehicles of the Internet and other consumer-empowering technologies, the customer has significant power and influence with WOM marketing (Elbedweihy, Jayawardhena, Elsharnouby, \& Elsharnouby, 2016).

Brand advocacy is the result of a deep business-customer relationship that is grounded in transparency and trust (Hassan, Rafi, \& Kazmi, 2016). Transparency and trust only come after a consumer's interaction with a business, not automatically. To build transparency a business owner needs to communicate with consumers honestly and directly (Khalifa \& Shukla, 2017). The consumer needs to feel an openness in both the nature and venues of communication. This honest communication is especially important when brand misconduct has occurred (Hsiao, Shen, \& Chao, 2015). By honestly interacting with his or her customers, a business owner can develop a trusting relationship that leads to brand advocacy. However, these interactions take time to develop and culminate in a strong bond between business and customer, they cannot be rushed.

Conversely, a consumer does not always have a favorable experience with a brand and may share through WOM avenues. This type of expression is negative word-ofmouth (NWOM) and could invoke significant detrimental effects on a brand by way of sharing a negative experience with a product or service (Jayasimha, Chaudhary, \& Chauhan, 2017). Not surprisingly, Hennig-Thurau, Wiertz, and Feldhaus (2015) determined that the type of tweet on the social media platform Twitter effected the diagnosticity, that is, the extent to which the tweet stood out to readers of the tweet. Negative tweets had higher diagnosticity than positive tweets (Hennig-Thurau, Wiertz, \& 
Feldhaus, 2015). The NWOM experiences the consumers share are meant to both cope with negative emotions and help future consumers. Consumers are not automatically swayed by group preference and NWOM. Khalifa and Shukla (2017) found consumers are more malleable to group influence on brand preferences when they dis-identify with a brand. However, if the consumer identifies with a brand and establishes the brand as a part of their self-identify, the consumer is no longer influenced by their peers (Khalifa \& Shukla, 2017). A business owner could mitigate NWOM sharing and influence by establishing a foundational consumer loyalty from initial business interactions. Whether this interaction is marketing communications, or the transactional purchase of product or service, makes no difference. Finding a match between brand and consumer is the first step in starting a successful stream of business interactions.

As time passes, consumers may enjoy business interactions with a brand and perceive the transactions to be both smooth and professional. When customers perceive their personality matches that of the brand, they form a strong connection with that brand (Hassan et al., 2016). They become devoted fans of certain brands and form a strong bond with the products or services offered by the brand. Moreover, the goal of business owners should be to create a healthy business-customer relationship highlighted by brand loyalty.

\section{Brand Loyalty}

Brand loyalty of the customer base is often the center of brand equity. Brand loyalty refers to the customer adherence to a brand or store (Aaker, 1991; Girard et al., 
2017). Powerful brand leaders can achieve high levels of customer awareness and loyalty, which help form a basis for building profitable and long-lasting customer relationships. When customers develop positive attitudes toward products or services that a business owner provides, these customer attitudes transfer over to the brand itself (Girard et al., 2017). The customer relationship between the brand, consumer, and brand loyalty, is malleable and multifactorial. Additionally, not all brand loyalty relationships are the same and are therefore divisible into different tiers.

A customer may have one of the several levels of brand loyalty. Each level embodies a different marketing challenge and a different asset to manage (Aaker, 1991). Aaker (1991) proposed that the lowest customer loyalty level is a non-loyal buyer who has indifferent buying behaviors to a brand. These customers may purchase for superficial reasons, such as simple convenience. Two levels of satisfied buyers are present within brand loyalty. A satisfied buyer can be a habitual buyer who does not currently possess a reasonable reason to change (Aaker, 1991). The more loyalty a customer possesses, the more satisfied he or she is with the current brand and deterred by the potential consequences of switching brands. The absolute highest level of brand loyalty is the committed customer (Aaker, 1991; Ali Mahdi, Abbas, Mazar, \& George, 2015). A committed customer takes pride in the product or service and becomes an ambassador for the brand. For example, a committed customer is the Macintosh user who puts a Macintosh sticker on the back window of her car and persuades her friends and family to buy Macintosh brand products. 


\section{Small Business Marketing}

Building a brand is a particularly difficult challenge for small business owners with limited resources, budgets, and time. According to Atanassova and Clark (2015), small- to medium-enterprise (SME) business owners require a foundationally different marketing strategy as compared to larger organizations. SME business owners are traditionally limited by their marketing resources (Franco, 2018). Successful SME business owners are aware of the initial struggles and issues facing his or her business versus the issues of a large-scale business with more than 500 employees. Franco specified the need for competitive advantage is more pronounced with SME business owners because the loss of a single customer can significantly affect firm survival. Because of the unique marketing needs and subsequent practices of small businesses, traditional marketing theory may be misaligned with SME marketing practices (Franco, Santos, Ramalho, \& Nunes, 2014). This misalignment requires a shift in the practical application of marketing strategies by these SME business owners.

Traditionally, large organization leaders tend to employ a classic top-down approach to interactive marketing practices, wherein the marketing strategies are driven by top-level administration and executives down to the ground-level employees (Torres \& Kunc, 2016). For example, a top-down communications marketing model would help marketers identify the overall design of the program and how well the program drives short-term sales as well a long-term brand equity (Batra \& Keller, 2016). Through this traditional marketing approach, executives create the marketing plan and a strategy to 
promote the company's products and services. For small business owners and marketers, the problem with traditional marketing approach is that, rather than the consumer, the business and products are the focal point.

In a so-called bottom-up marketing approach, a small business owner places the emphasis on the employees and consumers. SME business owners can use this approach to put networking and other relationship building marketing strategies at the forefront of their marketing plan enacted by employees (Franco, 2018). Employees are directly customer facing and can recognize and meet the needs of one specific customer with their products and services. These employees can create the marketing strategy around that single concept or idea (Atanassova \& Clark, 2015; Batra \& Keller, 2016). Business owners of SMEs tend to favor a bottom-up approach unique to their internal culture without long-term planning involvement (Atanassova \& Clark, 2015). SME business owners and marketers have greater flexibility in their marketing plans because their company size and structure allow a more responsive business nature to meet customer needs.

Small business owners can employ marketing technology faster than can large organizations. Yet there is a paucity of relevant literature for small business owners (Alford \& Page, 2015). Boyer, Edmondson, Baker, and Solomon (2015) attempted to bridge the gap between anecdotal evidence and three different marketing strategies, including traditional and covert marketing. Boyer et al. found contemporary covert marketing strategies had favorable results over traditional marketing strategies, although 
not all small business owners use such emerging marketing technologies. Lack of knowledge of the marketing technology seems to be the greatest barrier to implementation. Alford and Page (2015) determined that SME business owners' ability to take advantage of new technology was constrained by ignorance and inability to assess return on investment. A business owner's ignorance of emerging marketing technologies and its benefits could affect the marketing plan holistically.

\section{Pricing of Services}

A business owner can take several approaches when choosing the price of a product or service. Several common examples include peak pricing, penetration pricing, prestige pricing, and, psychological pricing. Peak pricing and penetration pricing are complementarily related to initial marketplace offering and the price paid for innovative products or services (Tălpău, 2014). The major drawback of these two pricing methods is the short-lived nature of their premium pricing. It is difficult for the small business owner to always provide innovation in their products and services and initial marketplace penetration only lasts for a short period. Prestige pricing and psychological pricing are more sustainable in theory. Prestige pricing is a high level price set on the perception of high product quality commonly seen in luxury brands (Khalifa \& Shukla, 2017; Kwon, Ratneshwar, \& Thorson, 2017; Tălpău, 2014). Prestige pricing is sustainable if the product or service remains of superior quality to the competitors in the marketplace. Finally, Psychological prices are based on the consumer's emotions as the consumers 
contemplate and interact with the product (Tălpău, 2014). Psychological pricing relies on non-rational consumers and a business owner with questionable pricing ethics.

Two additional pricing examples include the economic value approach and perceived value of product approach. Each of these approaches has advantages and disadvantages. The top advantage of the perceived value of product approach is the profit margins can be much higher. The major drawback is that consumers are more informed than in the past (Van Noort, Antheunis, \& Verlegh, 2014). Decades ago, a less informed consumer might assume that the high retail price of a product might reflect manufacturing costs; now, costs of manufacturing products and bringing them to market are available on the Internet. Use of the Internet significantly reduces office and distribution costs which allows consideration of alternative pricing methods. In the traditional retail environment, $10-15 \%$ of the price is the cost of physical logistics such as storage and delivery (Tălpău, 2014). If enough customers believe a brand's creators misled them, they will likely not purchase the brand again and will say so via social media such as Facebook and Twitter (Newman \& Dhar, 2014).

A much different approach is necessary when marketing a physical therapy service compared to a product. Relying on the customer-business relationship and identifying brand are key service customer retention traits (Tălpău, 2014). Although consumers' perceived thoughts and emotions about a brand are important when purchasing a product or service, these are most important when marketing a service. If the customer believes the brand's services are priced too high, he or she may decide not 
to purchase the product (Sloan, 2015). Consumers are emotional beings who identify with the way a brand makes them feel as an individual, which affects customer retention.

\section{Customer Retention}

Business researchers have proposed it is easier to retain current customers than to attain new ones. Most companies aspire to create goods and provide services that foster repeat business (Chahal \& Bala, 2017; Min, Zhang, Kim, \& Srivastava, 2016). G. King, Chao, and Duenyas (2016) argued a business owner should consider spending fewer efforts in both acquisition and retention of customers once the customer base is large enough. However, before this point of equilibrium greater profits are seen by customer retention efforts than acquisition efforts. Business owners often make the mistake of maintaining a growth model by focusing on gaining new customers. However, customer retention could be more important for financial health and survival of a firm than gaining new customers (Alshurideh, 2016). When a customer is lost, the business owners not only lose the current sale; they are likely to lose all profits for the lifetime of purchases a consumer can make (Alshurideh, 2016). Moreover, the cost of selling to current customers is lower than the cost of finding new customer sales. Alshurideh encouraged customer acquisition to be the secondary rather than primary goal of customer retention and current customer relationship enhancing efforts.

New customers can be consistently difficult to attract as they have minimal reason to consider switching brands. Once a business owner does acquire a new customer, they often buy $10 \%$ less than current customers and are less engaged in the construction of a 
customer-business relationship (Alshurideh, 2016). Business owners often invest significant time, energy, and expense to alter their product or service without fully understanding how these alterations affect the retention of existing customers (King et al., 2016). Additionally, the business owners may not have differentiated the product or service features that attract new customers from those features that retain current customers.

Customer retention cannot be controlled by giving away free services or products. Datta, Foubert and Van Heerde (2015) discussed the value of customer retention depending on current customer status in a service industry. For example, the value of a free trial customer is worth less than pay-per use customers because of the higher churn rate of free trial customers (Datta et al., 2015). In fact, the customer lifetime value to a business can be $59 \%$ less than that of regular customers in the service industry (Datta et al., 2015). The good news for business owners is that because of the infancy of the service relationship, interaction history is minimized, which leads free-trail customers to rely more heavily on direct marketing communications when deciding to retain a service compared to regular customers (Batra \& Keller, 2016; Datta et al., 2015; Hamilton, Rust, $\&$ Dev, 2017). Business owners can target more direct marketing at free trial customers, and other marketing methods at regular customers.

The key to customer retention is to minimize a dissatisfied customers' motivation to leave the brand while simultaneously leveraging the switching costs of those customers happy with the brand performance (Aaker, 1991; Tamaddoni, Stakhovych, \& Ewing, 
2017). A business owner may solicit lost customers to analyze the impairments causing the customer to switch brands. Additionally, an aggressive customer retention plan will surpass sources of customer frustration to mounting switching costs by consistently incentivizing current customerd, such as by a customer rewards program.

New and current customers can be affected differently by the same service and attribute different values to the same service. Tamaddoni et al. (2017) determined the features that retain current customers are often different from those that attract new customers. For example, a greater number of product features does not improve customer satisfaction and can, in fact, be detrimental to customer retention (Tamaddoni et al., 2017). Paradoxically, new customers tend to prefer services or products with more amenities or features (Datta et al., 2015). For example, subscription-based providers such as Netflix offer free trials to attract new customers, hoping to recuperate their free trial investment when customers become paying subscribers. Business owners use this tactic to begin building a relationship with their customers through marketing. Managers desperate for short-term financial results have often unwittingly damaged their brands through price promotions and unwise brand extensions (Aaker, 1991). A major contributor to customer retention is the apparent relationship between the brand and the customer.

\section{Relationship Marketing}

Relationship marketing refers to the process of interactions between the brand and the customer viewed as a relationship, rather than a transaction. Relationship marketing 
was initially coined in the 1990s as a subtopic of market focused management (Zinkhan, 2002). Relationship marketers approach sales from a different viewpoint than a traditional marketing strategy. Marketers using a traditional marketing strategy are focused on the single transaction between a company and a customer. From the viewpoint of the business owner, traditional marketing ends at the completion of the consumer business transaction with little thought to the future business transactions. A relationship marketer views the investment in the long-term customer interaction as an asset taking priority over the one-time exchange of a good or service. If a customer chooses to stay loyal with a brand long-term the brand has demonstrated customer retention assets, which is highly beneficial for brand health, especially in the service industry (Thi Minh Pham et al., 2016). McCrory, Pilcher, and McMillan (2017) discussed a practice-based framework to improve customer retention that includes the three key areas of culture, continuous improvement, and customer service.

Customer retention is important for new small business owners launching, growing, and sustaining new businesses. Poor customer service cited as a leading reason $70 \%$ of customers leave a brand (McCrory, Pilcher, \& McMillan, 2017); retaining customers costing significantly less than attracting new customers (Alshurideh, 2016). Customer service begins with the culture of the company providing the service to the customer. Leaders influence customer culture, which needs to be malleable to hit the moving target of customers changing requirements (Kaufman, 2015). Business owners that create a company culture embracing openness and change foster a model of 
sustainability and growth with adaptable customer service markers set their business up for successful customer relationships (Elbedweihy et al., 2016; McCrory et al., 2017). Moreover, business owners who demonstrate adaptable and open company cultures are consciously creating a cyclic model of continuous improvement, such as The Toyota Way model (Jayamaha et al., 2014). These tenets of adaptable and open company culture, continuous improvement, and quality customer service demonstrate a good model of relationship marketing mix.

A successful physical therapy business owner recognizes that his or her business provides services optimal for relationship marketing benefits. These optimal relationship marketing benefits are dispersed to both the patient and the referral source. The physical therapy practice owner should initially foster the relationship with the referral source to get the patient into physical therapy services. Although direct access to physical therapy services saves the United States health care system significant health care costs, most patients are unaware they can directly see a physical therapist (Piano, Maselli, Viceconti, Gianola, \& Ciuro, 2017). Therefore, physical therapy practice owners are forced to rely on referral sources including physicians who are under referring patients to physical therapy (Dennis, Watts, Pan, \& Britt, 2018). If physical therapy practice owners enhance the relationship with referring physicians, they could positively affect patient referrals to their clinic.

Physical therapists routinely treat patients for multiple sessions over weeks and even months (Babatunde, Macdermid, \& Macintyre, 2017). If patients do not like their 
physical therapist, they may not return to their next treatment session, or self-discharge from physical therapy services altogether. From an objective standpoint, several physical therapy researchers have found a linear relationship between patient outcomes and how the patient feels about their therapist (Ferreira et al., 2013; Fuentes et al., 2014). Physical therapy is, therefore, a relationship dependent interaction between the physical therapist and the patient.

A business relationship called therapeutic alliance exists between the customer receiving care, the physical therapist, and the physical therapy practice business owner, unified toward the patient's goals for physical therapy (Fuentes et al., 2014). The hallmarks of a positive therapeutic alliance in physical therapy are improved outcomes and patient adherence to therapy (Babatunde et al., 2017). These hallmarks are necessary for a small physical therapy business owner to sustain a successful outpatient clinic.

\section{Word-of-Mouth Marketing}

Successful small business owners in the service industry respect the power of WOM marketing. WOM marketing is the most current and important channel of communication with consumers (Batra \& Keller, 2016; Boyer et al., 2015; Cheung \& Thadani, 2012; Hennig-Thurau et al., 2015; King et al., 2014; Mukherjee \& Shivani, 2016). In the past, traditional marketing centered on mass media, including hardcopy ads and TV commercials consumers later retrieved from memory (Batra \& Keller, 2016). Now customer generated advertising leads to the purchase of a product or service. 
With the increased social media outlets, consumers are distracted by different media sources, which affects their advertising information processing and purchase behavior holistically. Now, this consumer path to purchase is no longer a clear, straight line but a convoluted path through online social media, search engines, blogs, review platforms, and product or service websites (Batra \& Keller, 2016; Fulgoni, 2015; Kwon et al., 2017). Specifically, marketing researchers have found a direct relationship between WOM marketing and brand sales performance. Gopinath, Thomas, Krishnamurthi (2014) found that not all online WOM is the same in relation to sales influence and staying factor. In fact, advertising that creates rational messages has less online staying power compared to emotional biasing advertising. Gopinath et al. found that the quantity of WOM has no significant influence on sales; the content of the WOM is more important. WOM communications by consumers can lead to comradery and a sense of belonging to a brand community.

Consumer loyalty can be affected by community engagement of a brand that provides local services (King et al., 2014). When the brand encompasses a brand community, extended customer-to-customer interactions heighten both customer engagement and brand loyalty. To capitalize on this phenomenon, King et al. (2014) proposed business owners encourage a select few loyal customers to generate high-value content and engage in electronic WOM practices. Septianto and Chiew (2018) reinforced this premise when they suggested the customer reviews are left soon after the customer experience with the brand. Amazon's business leaders initially implemented online 
consumer reviews, which differentiated it from all other online retailers and meaningfully improved consumer loyalty. Amazon.com website designers created an online platform to foster WOM communications, which led to increased consumer trust and a favorable online store experience (Koo \& Park, 2017). When new consumers are choosing a service, they have not yet experienced, they are reliant on WOM communications (Yaman, 2018). Through WOM communications potential customers consider perceived brand image and perceived quality as important factors affecting purchase preference (Yaman, 2018).

\section{Social Media Marketing}

Social media is not only a method of social connectivity and sharing usergenerated content but also to share consumer and business-related information. Given the unprecedented reach of social media, companies are relying on this media channel to improve marketing and customer communication (Holt, 2016; Kumar, Bezawada, Rishika, Janakiraman, \& Kannan, 2016; Raghupathi \& Fogel, 2015). Initially, business owners used the Internet to create webpages which were little more than mass media brochures in digital format. As the Internet became more accessible, easy to use, and inexpensive, small business owners have shifted their focus from the television mass marketing to social media based marketing campaigns (Batra \& Keller, 2016; Gensler, Valckner, Liu-Thompkins, \& Wiertz, 2013). According to Kumar et al. (2016), total spending on social medial advertising increased 56.2\% worldwide from 2013 to 2014. This statistic highlights the link between social media engagement and consumer sales. 
Social media marketing has several advantages over traditional marketing avenues. One distinct advantage of social media marketing is the ability to engage in both traditional mass marketing and mass customization strategies through a single venue (Alford \& Page, 2015). Small businesses that sell products can now offer a much larger inventory than they could every physically warehouse, eliminating the advantage of large retailers (Alford \& Page, 2015). Social media platforms have provided small business owners the opportunity to reach millions of potential customers in an inexpensive method over the Internet. Social media marketing works as a complementary marketing venue to other forms of marketing. Kumar et al. (2016) contended firm- generated content in social media works synergistically with both television and email marketing. For social media marketing to have an effective influence on the customer, the customer may need to be tech savvy and engaged with social media networking on a regular basis.

Business owners can use social media sites such as Facebook and Twitter effectively to promote their brand and relate information to potential customers. Facebook is the most widely used social media network with $67 \%$ of all online users in the United States engaging in Facebook use in 2015 (Raghupathi \& Fogel, 2015) with the usage percentage trending toward continued growth. In fact, users spend up to seven hours more per month on Facebook than all other common website search engines combined (Raghupathi \& Fogel, 2015). With such high usage numbers, social media exposure can have a significant and positive influence on consumers' likelihood to purchase as long a the customer trusts the social media site (Kumar et al., 2016; Xie \& 
Lee, 2014). For business onwers fostering trust in consumer generated posts is necessary to maximize social media influence. Another evolution of Internet marketing has been the transisiton from consumer generated blogging to microblogging. A few years ago the Internet was less user friendly and to blog about a product or service the user would have to write a full post on a website. This added complexity to the shared user experience and significantly limited the online traffic to the blog.

Currently, social media designers have reversed most of the blogging shortcomings with microblogging. Microblogging is a short posting that a user can post on Facebook, Twitter, and Instagram, as well as other social media sites (Hennig-Thurau et al., 2015; Wilburn \& Wilburn, 2016). These microblog posts on social media networks are quickly funneled through a multitude of social media channels drastically increasing the reach of the message. Social media network designers have inexpensively increased the number of consumers that see a consumer product or service message as well as improving the ease of user posting with microblogging (Hennig-Thurau et al., 2015), but microblogs are not without their shortcomings.

One major shortcoming of microblogs is their effect on consumer trust. Microblogging is a form of electronic WOM advertising which is a strong indluencer on consumer decision making for products or services online (Kucukemiroglu \& Kara, 2015; Raghupathi \& Fogel, 2015). Electronic WOM communications have two parties, the opinion leader, and the opinion seeker. The opinion leader exerts influnec on the opinion seeker if their message is credible if they are considered an expert on advice, and if they 
are trusted (Raghupathi \& Fogel, 2015). Opnion seekers are especially likely to trust an opion leader who conveys values similar to their own. For this reason, Facebook friends can offer significant encouragement to opinion seekers because they are already trusted (Raghupathi \& Fogel, 2015). Opinion seeking consumers percpetion of the person posting the microblog on Facebook is correlated with the purchasing behavior of the consumer. Raghupathi and Fogel (2015) found that if a posted advertisement was viewed as benevolent, as well as honest and truthful, thir intention to purchase the product was greater. Moreover, Mir (2015) concluded from his study on ad-clicking behavior in social media networks that ad-clicking was increased for banner ads if they were eye-catching and played to the consumer's emotions.

Given the siginificant potential influence of social media marketing, why aren't all small business owners focused social media marketing? The answer to this question is multifactorial and unique to each business owner. However, some common factors exist. For example, some business owners have social media trust concerns (Raghupathi \& Fogel, 2015). Kumar et al. (2016) suggested that a far majority of marketers are concerned about measuring the return on investment from social media advertising. Additionally, social media network sites are becoming more rigid in their related business policies. Facebook designers implemented rigourus changes to filter unpaid advertising in users' feeds placed by businesses erecting another barrier between business owners and their advocate consumers (Kumar et al., 2016). 
Lastly, not all consumers have healthy social media user experiences. Some consumers may have difficulty with self-monitoring of social skills on Facebook. An unwillingness or inablity to use self-monitoring on Facebook may make those users more susceptible to depression (Twomey \& O'Reilly, 2018). Park and Baek (2018) found a relationship bewtween social comparison on Facbook, emotions and psychological wellbeing. The effects of social coparison via social networking sites is positive or negitive depending on the social comparison on the user (Park \& Baek, 2018; Pera, 2018). Despite these findings, business owners should not abandon social media marketing, but instead employ a social media marketing strategy to emphasize the strengths of this tool.

A key marker of optimal social media marketing strategy is to use social media to communicate with other businesses and customers without trying to force the issue of sales. A much better tactic is to use social media to establish a cultural brand for the business (Holt, 2016). Marketing resources are a concern for all SME business owners (Franco, 2018). Social media marketing offers cost savings versus traditional marketing methods. For a small firm starting out in e-commerce, social media may be the best way to advertise while saving money to help build their IT infrastructure.

\section{Customer Communication}

The implications of interpersonal communications between consumers on the Internet can have in influence on product or service sales. Business owners should pay close attention to the interpersonal communication of consumers on the Internet (King et al., 2014). A consumer can participate in online communication through many venues 
including forums, text messages, instant messenger, chat rooms, blogs, and social media sites such as Facebook, Twitter, and LinkedIn. According to Riegner (2007), we now live in a never ending, emotional, social media atmosphere in which we can succeed as human beings in creating a connectedness to our environment. Additionally, business owners should carefully manage communications from business to consumer. Marketers use of Internet marketing strategies is rewriting the rules of engagement between consumer and business (Davvetas \& Diamantopoulos, 2016; Godey et al., 2016).The balance of advertising power has shifted from companies to the customer . Companies have invested billions of dollars into social media advertising hoping to gain an audience to support the brand (Agnihotri, 2013; Holt, 2016; Liu et al., 2017). According to Holt, this approach to gaining brand advocacy has been unsuccessful. Online customers have used social media to transmute how customers communicate with businesses. Digital crowds on the Internet have become market trendsetters, which researchers have named crowd culture (Holt, 2016). The sheer number of customers engaging in social media as a digital crowd can be overwhelming for business owners to keep up with (Gensler et al., 2013; Holt, 2016). As business owners strive to create their own crowd culture to support their brand via online communications with customers, conventional marketing branding strategies have suffered (Godey et al., 2016; Holt, 2016). companies to try and create on their own. Although marketers online crowd culture approach has harmed conventional branding efforts, it has caused the creation of an alternative branding model called cultural branding (Holt, 2016). 
Marketers can manage online communication with customers. One tactic is for companies to use celebrities to break through social media channels via product or service endorsements. Entertainers are extremely popular in social media and can affect consumer engagement with the brand and the media outlet (Holt, 2016; Opuni, Asiedu, \& Acheampong, 2014). Moreover, consumers are becoming the authors of brand stories through social media and sharing of brand experiences (Gensler et al., 2013). Business owners need to be extremely attentive to consumer generated stories and shared experiences and quickly highlight positive examples on social networks such as Twitter and YouTube to stay ahead of the crowd culture curve (Holt, 2016).

Retail marketers rely heavily on direct marketing for revenue growth and development. According to Lund and Marinova (2014) in 2012 retailers spent $\$ 10.7$ billion on direct marketing, representing $43 \%$ of total marketing expenditure. Although direct marketing is currently the greatest single category expenditure for retail advertising, some researchers have proposed that even more money could be spent in this category (Lund \& Marinova, 2014). While other researchers believe that direct marketing in the retail market should be replaced by an emphasis in the rapidly evolving field of digital marketing (Atwong, 2015).

Marketers that emphasize digital marketing harness primarily online strategies to draw a customers' interest and get them talking about products or services. This type of digital marketing strategy is called interactive marketing (Batra \& Keller, 2016; Kwon et al., 2017). Interactive marketing is in direct contrast to the top-down traditional style of 
marketing in which the product proposals are presented to the customer as a fixed, oneway message that the customer either accepts or rejects (Van Noort et al., 2014). Interactive marketing fits trending marketing approaches due to it is propensity to digitalization and a social media basis (Batra \& Keller, 2016). Brand equity and brand attitudes of the consumer correlate significantly with brand related interactive marketing (Schivinski, Christodoulides, \& Dabrowski, 2016). The conversation between users and brand marketers can lead to consumer engagement directly with the brand and future communications.

One of the strengths of interactive marketing is consumers can be involved directly with product development and innovation. Business owners that foster usergenerated product development and innovation ensure their product is a customized product for the consumer (Atanassova \& Clark, 2015; Godey et al., 2016). The major limitation of this innovation style is that consumers do not have business or content expertise and may lead the firm down a treacherous path (Atanassova \& Clark, 2015). Consumers may not have the business training to understand complex business topics such as product research and design, product development, manufacturing, distribution, and profit margins to ensure long-term success. Consumers could lead a firm down a pathway of financial ruin if allowed great freedom in innovation without appropriate management and guidance of their brainstorming (Styles \& Goddard, 2014). The company marketers' should utilize social networking sites to optimize their marketing campaigns and foster directed brainstorming (Styles \& Goddard, 2014). Marketers can 
make good use of interactive consumer elements by integrating into social networking sites to encourage not only the conversation but also self-disclosure of customer information (Van Noort et al., 2014). This information can be used to help marketers develop business intelligence on its consumers to guide product development (Godey et al., 2016; Kucukemiroglu \& Kara, 2015; Van Noort et al., 2014). Marketer's approach to managing their marketing mix variables may include social networking site utilization in the current era of personalized marketing.

\section{Managing the 5 Ps}

Successful marketing of products and services depends on the consideration of four key elements also traditionally known as the 4P marketing mix model. The 5 Ps are an adaptation of the 4Ps model that is well-established in business theory. 5Ps are product, price, placement, promotion, and people (Mukherjee \& Shivani, 2016; Tălpău, 2014). The product is the actual good or service that the company sells. There are three product levels the core product, actual product, and augmented product (Tălpău, 2014). To maximize the product marketing mix that marketers need to ask themselves several questions and be introspective while still gathering an external opinion from stakeholders and eventually consumers. These issues should address the product size, design, and shape. The unique features of this product and how does it compare and differentiate from its competitors (Mukherjee \& Shivani, 2016).

Price is the actual value of the product to a prospective customer. Marketers should determine what the market price is for their product or service and how much the 
customer is willing to pay to still consider the purchase a good buy (Ranjan Dash \& Mahakud, 2013). Prices would generate the actual revenue from the product and perceived attractiveness of the product not just actual cost of production should be considered and leveraged in a reasonable manner (Tălpău, 2014). A business owner should use dynamic pricing in an ethical way to improve revenue (Huang, Hsu, \& Ho, 2014). Many pricing strategies may work depending on the brand diffrerentiation strategy the business owner wants to employ.

Placement refers to product placement including where the product is sold, how efficiently it can be delivered to the consumer, and product or service accessibility (Martí-Parreño et al., 2017). Marketers need to ensure that the products and services are as easy to find as possible. Marketers must make sure that the sales outlet is optimized for their product or services. For example, it may be best for a company to offer its products or services direct to the consumers through e-commerce (Newman \& Dhar, 2014). Promotion is a complicated and expensive part of the marketing mix and involves how the marketers communicate to customers to generate sales. Promotion relates closely to product placement with the goal of promotion being to attract new customers while maintaining current customers and enticing them to increase their purchasing power.

Lastly, the people employed by an organization might have the greatest overall influence on the organization's success. Questions a marketer should ask include: Do we hire the right people to deliver optimum service to the customer? Selling products and services to consumers is all about building long-lasting mutually beneficial relationships 
(Girard et al., 2017; Godey et al., 2016). Some researchers have argued that the people employed by the organization have the greatest influence on consumer to business relationships (Van Noort et al., 2014). For marketers to be successful, they need to ensure that their employees have the proper attitudes, behaviors, and skill set to best serve the consumer. Small business owners should balance their $5 \mathrm{P}$ marketing mix to sustain their small business and prevent potential business failure.

\section{Small Business Success and Failure}

In the United States, a small business is defined as an organization having fewer than 500 employees. SMEs employ 99\% of U.S. workers, Researchers have long valued small businesses for their important role in maintaining economies (Gupta, Wilson, Gregoriou, \& Healy, 2014). SMEs fail at a higher rate than larger corporations, which suggests a bleak picture of the SME sector's future economic growth and job creation of which many economies are dependent upon.

Fatoki (2014) categorized failure as both internal and external factor. Internal factors include lack of management experience, lack of functional skills, and poor employee attitudes toward customers (Liao \& Cheng, 2014). External factors include supply chain management logistics, rising costs of doing business, and lack of startup financing. Perhaps the largest initial obstacle for a small business owner is securing adequate capital to launch the small business. A business owner can overcome this obstacle through effective use of external support systems. 


\section{External Support Systems}

External support systems can have a positive effect on small business owners and small business sustainability when properly used (Fatoki, 2014; Peterson et al., 2014;

Sullivan \& Ford, 2014). External support systems can cover the gamut of potential needs for small business startup. Examples of external support systems include funding sources such as the SBA, communications, and IT support, or even entrepreneurial mentors through programs such as the SCORE association. Access to funding resources is a pivotal challenge facing small business owners during early venture development (Sullivan \& Ford, 2014).

Every new small enterprise needs funding to get going and, in turn, to stay operational until it turns a profit. Two main ways to gain startup funding are either borrowing from a lender as debt capital or owners selling shares of the business to investors as equity capital (Staniewski, Szopiński, \& Awruk, 2016). The business owner's motive may affect the choice of capital funding source. Staniewski et al. found entrepreneurs with financial motives often use their funding resources or loans that will need to be paid back. Of 78 SMEs surveyed in Pakistan, banks played a positive role in the growth of the SME over a 3-year period (Khan, 2015). By contrast, Khan found that if informal sources of funding were used, there was a negative correlation to growth. Recently, small business owners have been looking for alternative financing methods.

Over the past several years, crowdfunding has become a means for small business owners to gain investments. Crowdfunding, a relatively new method of fundraising, pools 
a large quantity of investors' money to venture entrepreneurs with promising ideas for starting a business (Cichy \& Gradon, 2016; Mollick, 2014). Crowdfunding can be viewed through a strengths, weaknesses, opportunities, and threats analysis. The strengths of crowdfunding are a chance to test the marketability of a product or service before launch, accessibility of capital, and rights to keep the entrepreneur as the decision maker (Valančienė \& Jegelevičiūtė, 2013). The drawbacks of crowdfunding include exposure of business ideas to the Internet, where they can be stolen; weaker investor fraud protection; and administration challenges (Mollick, 2014). U.S. regulatory bodies have created a governing framework to allow small business owners to crowdfund without the strict requirements of traditional loan offerings.

\section{Health Care Marketing Plans}

Providing high-quality health care services for the older population is a problem for an aging world population. Outpatient health care services rely on the patient to volitionally choose to obtain services from the provider rather than inpatient services wherein the patient requires comprehensive service care at a hospital upon admission. Therefore, high-quality outpatient health care services, including physical therapy, should be marketed to consumers to raise customer awareness and foster consumer selection (Mou \& Shin, 2018). For growth and sustainability, business owners may implement a health care marketing plan that has the consumer at the top of the priority list. Such knowledge could be gained if consumers conveyed to marketers the role that advertising had in changing their attitudes and behaviors to produce change (Smith, 2015). Namely, 
this change would present researchers with an ability to measure how well advertising works on a set plan of objectives (Kash \& Deshmukh, 2013). Monitoring trend issue identification may be useful to determine the external environment's effect on physical therapy business owners' ability to attract new patients.

The initial step of using a trend application approach for marketing plan development is to identify the current trends of the brand. Trends are identified through customer survey research addressing customer purchase behavior, ethnographic analytics, customer retention data, brand engagement data, loyalty card data, and measures of brand loyalty (Belk, 2017; Schivinski et al., 2016). Current trend issues for physical therapy services include negative public perception, lack of referrals, busy patient schedule, local competition, and community involvement of the service (Kash \& Deshmukh, 2013). A business owner could analyze and rank these trends into two categories: potential influence and the probability of continuation (Kash \& Deshmukh, 2013). A business owner can then design his or her marketing plan to target the trends and issues that have the greatest potential influence and the highest probability of continuation first. Any marketing plan in today's small business marketplace would be incomplete without a social media marketing component.

\section{Physical Therapists' Business Education}

A small business owner's expertise and management experience can affect the performance of his or her small business positively or negatively. The small business owner's education should not be considered formal and static. Small business owners 
need to grasp the requirement for continued business education to improve their odds of sustainability. In the small business marketplace, a business owner has an important competitive advantage by having a previous business education (Dumitrache \& RaileanuSzeles, 2014). Small physical therapy business owners are often physical therapists themselves. Traditional physical therapy education programs provide a limited amount of small business coursework and exposure.

The Commission on Accreditation in Physical Therapy Education (CAPTE) is an accrediting agency for physical therapy programs in the U.S. The CAPTE is nationally recognized by the Department of Education and mandates standards for these programs. The current CAPTE standards include entry-level mobile education on finance and fiscal management of patient care and payment as well as practice management education (Christensen et al., 2017). However, the details and magnitude of this business-based education component are vaguely defined and one of the last mentioned competencies (Christensen et al., 2017). By de-emphasizing business in entry-level physical therapy programs, CAPTE has allowed these programs to offer limited entry-level credits on this topic, with most surveyed schools have a single business-based course (Christensen et al., 2017; Rundle et al., 2016). Since many small business owners of physical therapy practices are physical therapists, a distinct need to improve entry-level business education is present to ensure an adequate supply of physical therapy services for the perpetually increasing demand. 


\section{Transition}

I began Section 1 of this study with the background of the problem, problem statement, purpose statement, nature of the study, research question, interview questions, conceptual framework, operational definitions, assumptions, limitations, and delimitations, and finally the literature review. Section 2 provides information on the (a) role of the researcher, (b) selected participants, (c) research method and design, (d) data collection and analysis, and (e) the reliability and validity of this study. In Section 3, I will present an introduction to the study, presentation of findings as related to the brand equity model conceptual framework, implications for positive social change, reflections, summary, and conclusions. 
Section 2: The Project

This section includes a discussion of the method for studying the marketing strategies used by small business owners of physical therapy practices to sustain their business for 5 years. I begin by restating the purpose before addressing the role of the researcher, participants, research method and design, population, and sampling. In this section, I also discuss ethical research application, data collection, data analysis, reliability, and validity.

\section{Purpose Statement}

The purpose of this qualitative multiple case study was to explore physical therapy practice owners' marketing strategies for sustaining their businesses beyond 5 years of operation. The targeted population for this study was comprised of five owners of five physical therapy practices in northeast Florida who have successfully implemented marketing strategies to sustain their business beyond 5 years of operation. The implication for positive social change included the potential to increase physical therapy services to those in need of rehabilitation in northeast Florida.

\section{Role of the Researcher}

In a qualitative multiple case study design, the researcher has many roles.

Qualitative researchers do not usually use instruments; rather, they are the key instrument of the study (Miller, 2015). Researchers can use multiple forms of data collection including interviews, participant observations, and company documents (J. Park \& Park, 2016; Patterson \& Malpass, 2015). As the researcher, I was responsible for the design 
and data collection, as well as reporting and interpreting the findings. I conducted faceto-face interviews, collected observational data of participants during the interviews, and analyzed company marketing documents.

I have an intimate relationship with the field of physical therapy. At the time of this study, I was a full-time educator but by trade a physical therapist. Additionally, I lived and practiced in the geographic location of my purposeful sample, a potential weakness of the study if participants have had a professional physical therapy relationship with me. This geographic proximity can be a necessity to gain reasonable access to participants in qualitative research (Fjellström \& Guttormsen, 2016). A researcher should not show bias toward the topic of study, geographic location, or study participants (Barnham, 2015; Krefting, 1991; Miyazaki \& Taylor, 2008). Additionally, qualitative researchers have proposed bracketing is used to prevent bias from entering interviews (Sorsa, Kiikkala, \& Astedt-Kurki, 2015). Although researchers affect the qualitative process of data collection during participant interviews, bracketing allows the researcher to set aside any previous understanding of the topic and act in a nonjudgmental way toward the participants (Sorsa et al., 2015). I adhered to these research guidelines and mitigated bias using bracketing throughout the data collection process. I used semistructured interviews to gain marketing strategy data from the business owners participating in this study. Birt, Scott, Cavers, Campbell, and Walter (2016) advocated for a standardized interview approach when conducting participant interviews. Management researchers have suggested a step-by-step, predetermined process to collect, 
code, analyze, and recheck the data in study (Van Den Berg \& Struwig, 2017). I used an interview protocol (Appendix A) to minimize my personal biases during the interview process and ensure the interview questions align with the purpose of the study. I selected a sample of five small physical therapy practice owners for my study. To mitigate my personal bias as a physical therapist living in this geographic region, I did not select business owners with whom I have had a professional relationship. A third-party vendor transcribed the interviews after the data was collected. The transcription vendor signed and returned a non-disclosure agreement to protect participant data (Appendix B). I sent the transcribed interview to the participant for a review as part of the transcript validation process. After making any corrections requested by the participants, I used NVivo to identify the themes of the interview data.

The U.S. government drafted the National Research Act of 1974 to identify foundational principles of ethics in human subject research to ensure subject protection and fair treatment (Bromley, Mikesell, Jones, \& Khodyakov, 2015). The Belmont Report was written by the National Commission for the Protection of Human Subjects of Biomedical and Behavioral Research after three years of deliberations and published in 1979 (Bromley et al., 2015; Rogers \& Lange, 2013). The Belmont Report has three main tenets: respect for persons, beneficence, and justice (Rogers \& Lange, 2013; Vitak, Shilton, \& Ashktorab, 2016). I followed the tenets of the Belmont Report by providing each participant with an informed consent providing, per the Belmont Report, the purpose, procedure, and the participant rights for this study. Participants' health and well- 
being was not affected by their participation in this study. To further ensure adherence to the Belmont Report principles, I submitted my study to the Walden University IRB and received approval prior to data collection.

\section{Participants}

The purpose of this study was to explore the marketing strategies of small physical therapy practices owners use to sustain their business past 5 years of operation. The participant pool in this study was outpatient physical therapy practice owners located in northeastern Florida who have successfully implemented marketing strategies for sustaining their businesses beyond 5 years of operation. Researchers using a qualitative study design recruit their study participants using purposive sampling (Miller, 2015; Staller, 2015a). I began by asking professionals and members of the local chamber of commerce and the SBA of North Florida for help identifying small physical therapy practice locations and their owners in northeast Florida. To ensure all participant characteristics align with the research question, the participants were small physical therapy practice owners located in northeastern Florida who have successfully implemented marketing strategies for sustaining their businesses beyond 5 years of operation.

Once identified, I sent emails and made telephone calls to owners of these therapy practices, gave them information about the study, and requested their participation. Potential participants who acknowledged they are willing to participate in the study completed the informed consent form (Mayer, 2015; Miller, 2015; Saxena, 2017). Once 
all participants were identified, I interviewed each participant until data saturation occurred. Data saturation was noted when the interview and data analysis process no longer provides new information and instead reaffirms previous data and trends (Lawrence \& Tar, 2014; Yin, 2014).

One challenge that qualitative researchers face is establishing a successful level of rapport and trust with the participants (Patterson \& Malpass, 2015; Staller, 2015b). Patterson and Malpass (2015) recommended purposeful strategies to establish a working relationship between the interviewer and the participants. A researcher initiates that relationship by emailing and speaking with participants at the beginning of the data collection process (Saxena, 2017; Staller, 2015b). The next step, administering an informed consent and answering any participant questions about the study, can solidify trust and rapport between the researcher and participants (Anney, 2014; Kornbluh, 2015). I started the relationship building by contacting potential participants via email with an introductory letter. I followed up with an email to appropriate volunteering participants with the informed consent and began the open exchange with the participants to answer any questions they had.

\section{Research Method and Design}

I used a multiple case study method to explore physical therapy practice owners' marketing strategies for sustaining their businesses beyond 5 years of operation. A successful qualitative researcher uses a multifactorial approach to research methods, including multiple sources of data, triangulation, a theoretical framework lens, and his or 
her skills as a researcher to accurately depict the issue and participant solutions (Belk, 2017; Miller, 2015; Staller, 2015b).

\section{Research Method}

A researcher has three distinct methods of research to choose from: quantitative, qualitative, or mixed methods. A quantitative researcher is independent of the research and uses an impersonal voice to test a theory (J. Park \& Park, 2016). Although quantitative research is more objective than qualitative research methodology, it does not let the researcher observe and interpret data in the participants' context (Miller, 2015; Yin, 2014). Ultimately, the goal of the qualitative method is to explore the accounts of social events in natural settings (J. Park \& Park, 2016; Reinecke, Arnold, \& Palazzo, 2016). Through a mixed-method design, the researcher engages in a combination of quantitative and qualitative methods to answer a shared-approach research question (Venkatesh et al., 2016). I only used a qualitative approach for this study. A qualitative research method was the most appropriate method for this research study to gain an understanding of underlying reasons for the marketing strategies of small physical therapy practice owners.

The research method must best match the intent of the research based on multiple factors, including the purpose of the study and research question (Brawley \& Pury, 2014). The research question for this study was, "What marketing strategies do owners of small physical therapy practices use to sustain their businesses beyond 5 years of operation?" I best answered this research question using a qualitative approach. Researchers use 
qualitative methods to explore a deeper understanding of a phenomenon that subjects experienced (Chowdhury, 2015; Hyett, Kenny, \& Dickson-Swift, 2014). Researchers use the quantitative method to seek causal relationships and test theories in an objective manner (J. Park \& Park, 2016). The purpose of this study was to explore small business marketing strategies that physical therapy practice owners use to sustain their businesses past 5 years of operation. The purpose of this study was neither objective or related to hypothesis testing. I used a qualitative research method to specifically explore successful marketing strategies of physical therapy practice owners through the extensive use of multiple types of data and reflect the participants lived experiences. Therefore, a qualitative research method was the best fit for the purpose and research question of this study.

Only through the complex and time consuming task of data analysis can a qualitative researcher relate the participants' lived experiences with the purpose and research question (Saxena, 2017). In the qualitative research method, the researcher serves as the main research instrument. Qualitative researchers focus on the meaning of a research question in its context, which requires a data collection instrument that is sensitive to underlying meaning while gathering and collecting data (Belk, 2017; Miller, 2015; Reinecke et al., 2016). In this qualitative study, I interviewed and observed small physical therapy practice owners and then analyzed the collected data to answer the research question and align my practices with the purpose of the study better than using a quantitative or mixed methods approach. 


\section{Research Design}

I considered four research designs for this qualitative study. The four qualitative research designs are: (a) phenomenological, (b) ethnographic, (c) narrative, and (d) formal case study (Runfola, Perna, Baraldi, \& Gregori, 2017; Yin, 2014).

Phenomenological researchers employ a philosophical approach to qualitative design commonly deployed in psychology, sociology, and social work to inform the reader about how subjects experience and interpret the world (Levitt, 2016). Ethnographic designs focus on the study of a culture of a group in which the researcher often becomes immersed as a participant (Hammersley, 2016; Yates \& Leggett, 2016). Narrative research is best suited to capturing detailed experiences of a single or a small number of individuals as lived (Carless \& Douglas, 2017). The last and best suited qualitative research design for this project is a case study.

Case studies are an intensive study of a specific individual or context. Case study researchers focus on the environmental analysis of an event or condition and the underlying relationships (Sayre, Toklu, Ye, Mazza, \& Yale, 2017). Case study researchers are varied in their approach but consistently use direct observation, interviewing, and document review to reach accurate theme detection and ensure the reliability of data saturation (Kasim \& Al-Gahuri, 2015; Runfola et al., 2017; Yin, 2014). Data saturation is a necessary component of any qualitative research that has content validity (Anney, 2014; Graue, 2015; Kerr, Nixon, \& Wild, 2010). Through data collection and constant comparison of themes, a researcher should continue data 
collection until no new variations of themes emerge (Bekhet \& Zauszniewski, 2012;

Chowdhury, 2015). I collected interview data, direct observation during participant interviews, and marketing strategy document review until the data became redundant. Researchers improve the quality of the study through data collection until data saturation but diminish if interviews continue (Marshall, Cardon, Poddar, \& Fontenot, 2013). After achieving data saturation, I discontinued data collection.

Multiple case studies involve the intensive study of multiple individuals designed to suit the research question and have become increasingly popular (Hyett et al., 2014; Yin, 2014). Through a multiple case study design, researchers explore in-depth participant perspectives in context (Lawrence \& Tar, 2014). Multiple case study designs are comparatively advantageous to a single case study in achieving data saturation. Yin (2014) suggested that conducting five or more case studies is analogous to five or more research experiments on a topic. Once the researcher has determined common themes and reached redundancy, further case evaluation will not change the study outcomes. Thus, I explored successful marketing activities of small physical therapy practice owners best through a multiple case study research design.

\section{Population and Sampling}

The population for the study consisted of 5 physical therapy practice owners in northeastern Florida who employ fewer than 50 employees. I gathered this purposive sample from independent outpatient physical therapy service providers within 30 miles of Jacksonville, FL. As suggested by Chalal and Bala (2017), Puryear et al. (2008), and Yin 
(2014), I used purposive sampling to ensure shared characteristics for variables to be considered in this study such as practice size, ownership, practice location, and services provided. In this study, I focused on the marketing strategies of small privately-owned physical therapy practices which specified the sample population as the practice owner responsible for marketing duties. Additional eligibility criterion for participant selection was that study particpantes had continously operated their physical therpay pracitce for a minimum of 5 years and had fewer than 50 employees.

As the researcher for this study, I collected data from study participants until data saturation was achieved. Researchers develop insight into the experiences of the participant as related to the phenomenon in question (Saxena, 2017; Sutton \& Austin, 2015). As one participant's narrative informs the next, I continued to gather data through interviewing until nothing new was heard and saturation of data was attained.

Researchers use data saturation to ensure trustworthiness of their findings (Anney, 2014; Chowdhury, 2015; Graue, 2015). Through data coding and theme identification; I reinforced that data saturation occurred. After the interviews were transcribed, I conducted transcript validation, so each participant agreed to the comprehensiveness and accuracy of their transcript. I made any participant recommended corrections to the transcript.

As Koelsch (2013) and Sutton and Austin (2015) recommended, conducting interviews at a location and time convenient for the participant can create a welcoming interview environment. I conducted face-to-face interviews with the participants in a 
location and time of their choosing to foster a successful interview environment and ensure the reliability of the interviews. Researchers use face-to-face interviews to conduct a direct observation of participants, thereby enhancing interview reliability as compared to phone interviews (Belk, 2017). I started the interviews restating the purpose of the study and study processes. To minimize participants' anxiety about the questions, I started with the business owners' relevant background information. During the interview, I answered any questions that arose at any time.

\section{Ethical Research}

I ensured all ethical principles and guidelines while completing this study. As a standard of research practice with human participants, I adhered to the Belmont Report of 1979 principles throughout this study. The Belmont principles include three guiding pillars concurrently upheld by the Walden University IRB: beneficence, justice, and, respect for persons (Bromley et al., 2015; Rogers \& Lange, 2013; Vitak et al., 2016). I maximized the benefits to the study participants by providing them access to this study upon completion and minimize any participation risks. Wendler and Abdoler (2010) proposed beneficence in research by minimizing study risks while maximizing benefits. There were no further participation incentives. Additionally, I ensured the equal burden of all participants with an interview protocol and respected participant autonomy through the informed consent process.

I received approval from the Walden University IRB (Approval No. 08-01-180625175) before any participant recruitment or contact was made. To protect study 
participants, I acquired informed consent from all study participants. In research involving human participants, all participants must understand their contributions to the study in layperson terms (Sutton \& Austin, 2015; Yin, 2014). The participant consent form covers background study information, study procedures, the voluntary nature of the study, risks and benefits, payment, privacy, and researcher contact information for further questions in nontechnical language. Along with the informed consent, I included an invitation form requesting study participation. A participant was free to turn down the study invitation or stop participation at any time with or without formal researcher notification. I communicated via email with potential participants who were not chosen that they were not selected for the study. Once the informed consent was signed and received, I provided an interview request letter including the in-person interview questions.

As the researcher, I protected participant confidentiality and privacy. I used a coding system to organize participants data while protecting the participant and business names. Coding is a form of qualitative methodology that can enhance researcher pattern recognition while minimizing subjectivity (Chowdhury, 2015; Stuckey, 2014; Yin, 2014). Furthermore, I stored the electronic study data securely in a password protected file on a locked computer, and any hard copy participant information was stored in a locked filing cabinet. All research documentation and electronic data will be stored for 5 years and then destroyed to protect the confidentiality of participants. 


\section{Data Collection Instruments}

In qualitative studies, the researcher acts as the primary data collection instrument (Belk, 2017; Miller, 2015; Reinecke et al., 2016). The researcher uses all of his or her senses during data collection to intake, code, and then interpret the data (Van Den Berg \& Struwig, 2017). I was the primary data collection instrument in this study.

A qualitative researcher may use structured, semistructured, or open conversation interview structures. Bromly, Mikesell, Jones, and Khadyakov (2015) used semistructured interviews with academic investigators to determine ethical priorities and challenges used during community health research. Yurdakul, Atik, and Dholakia (2017) found that semistructured interviews were a foundational portion of their qualitative methods to provide deeper insights on the sociocultural dimensions of the bottom of the pyramid consumers. Additionally, Berends, Jelinek, Reymen, and Stultiëns (2014) proposed that semistructured interviews with small business owners are the primary qualitative method one uses to establish adequate details related to the research question. Therefore, I used semistructured interviews to explore marketing strategies that successful small business owners of physical therapy practices use to sustain their business past 5 years of operation.

An interview protocol minimizes bias and ensures all required information is covered (Berends, Jelinek, Reymen, \& Stultiëns, 2014; Bromley et al., 2015; Yurdakul, Atik, \& Dholakia, 2017). I used an interview protocol to ensure the accuracy and reliability of my semistructured interviews (Appendix A). This interview protocol 
included nine preconceived interview questions related to small business marketing strategies with the final question providing an opportunity for the participant to speak freely about the topic. Additionally, the interview protocol included specific researcher directions on informed consent reminders and a section to record researcher reflections.

Qualitative researchers can further improve the reliability and validity of semistructured interviews after data collection has occurred. The most common method is member checking. According to Birt et al. (2016), member checking is one of the most common validation techniques for qualitative research involving participant recorded data. The researcher can use member checking to improve the credibility of the results (Koelsch, 2013). Of all member checking techniques, returning interview data or results to the participant to check for accuracy and reverberation of their lived experience is primarily done by transcript review (Birt et al., Stuckey, 2014; Van Den Berg \& Struwig, 2017). Once the interview dialogue is transcribed, I sent interview copies back to study participants for their initial review.

After the participant review, I made all suggested changes on behalf of the participant to ensure the accuracy of the transcription. This member checking process needs to occur before data theme identification to ensure the accuracy of data analysis (Koelsch, 2013; Mayer, 2015). The researcher can apply additional member checking techniques such as providing participants with the identified themes and give participants the chance to engage with and add to their experiences (Birt et al., 2016; Sutton \& 
Austin, 2015). I provided all study participants with the identified data themes after the interview transcriptions had been corrected and analyzed.

\section{Data Collection Technique}

The researcher chooses data collection techniques that connect the research question with the procedures. I used multiple data collection techniques specific to this qualitative case study process and research question. The research question for this study was, "What marketing strategies do owners of small physical therapy practices use to sustain their businesses beyond 5 years of operation?". Birt et al. (2016) chose multiple data collection techniques including in-depth, semistructured interviews and member checking to understand the experiences of their participants.

I conducted face-to-face interviews as the primary data collection technique for this study. Face-to-face interviews have several advantages over phone interviews. Through face-to-face interviews, researchers gain insight and context by asking clarifying questions, as well as building rapport through direct participant observation and interactions (Belk, 2017; Stuckey, 2014; Van Den Berg \& Struwig, 2017). To improve participant comfort, the face-to-face interviews took place in locations participants themselves choose.

Participant chosen environments place the researcher directly in the environment that allows them to make important observations (Fjellström \& Guttormsen, 2016). Qualitative researchers have reported on observations such as participant body language, physiognomy, and gestures, which cannot be observed over the phone. Wendler and 
Abdoler (2010) discussed a level of participant mistrust that may occur during in-person interviews. One shortcoming of face-to-face interviews is that some participants may not be open and honest with the researcher if they do not feel comfortable with the researcher (McIntosh \& Morse, 2015; Wendler \& Abdoler, 2010). I built a relationship with participants in a serial manner at each phase of participant interaction, beginning with the initial invitation to participate. Additionally, I reviewed company documents related to marketing strategies or examples of marketing materials.

When researchers review company documents they have the advantage of a broader context for understanding the participants responses during interview (Dasgupta, 2015; Kornbluh, 2015). Other authors have noted that archival documents can be used to add robustness and a comprehensive overall impression of the data (Das, Jain, \& Mishra, 2018). The further evidence of archival documents enhances triangulation of sources (Yin, 2014). However, there are several disadvantages of using company documents in qualitative research. One disadvantage is reporting bias of the author or participant (Das et al., 2018). The chosen documents may reflect the opinion of the person who chose them, which is a potential source of bias (Miyazaki \& Taylor, 2008). A second disadvantage is access to archival data may be withheld by participants or their employers (McIntosh \& Morse, 2015). Although a researcher takes known risks with archival document use, I used company marketing documents for the advantages of data context and robustness. 
Member checking is an important part of the participant data validation process. Qualitative researchers can lessen the member checking procedure by limiting it to interview transcription review alone (Birt et al., 2016). To demonstrate the adequate validity of the study data, I engaged in a multistep member checking process. The first step was paraphrasing the participant's responses to the interview questions. The next step was participant transcription review. Once received from the transcription service, I emailed the complete transcribed interview data to participants and encouraged their review and correction of any data therein. Lastly, I made participant requested corrections to the transcription before I charted and mapped the data. Once I charted and mapped the data, I used NVIVO coding software to manage data coding and identify themes. Many qualitative researchers have used NVIVO in case study research and found it to be an accurate and precise method of theme identification (Alford \& Page, 2015; Berends et al., 2014; Gardner, Samuel, \& Williams, 2015; Yates \& Leggett, 2016). In addition to direct data collection with the participant and the data analysis, I also reviewed documents submitted by participants.

Researchers review company documents to provide copious information adding context and detail to participant interview data (Miller, 2015; Yin, 2014). I obtained and reviewed company marketing materials, marketing plans, and websites for the participants' physical therapy business to associate with the interview data. All study data and documents will be stored electronically in a secured computer or a locked filing cabinet for 5 years before being destroyed. 


\section{Data Organization Technique}

To complete this study, I collected interview transcription data, business marketing plans, and marketing examples from the participants. Chowdhury (2015) advocated organization of data to ensure accurate usage, analyses, and protection of important participant information. Moreover, Staller (2015a) noted that many researchers employ techniques such as organized coding and thematic analysis successfully and productively to keep data organized. Stuckey (2014) stated qualitative researchers should be both structured and yet remain creative as they organize and then process their study data.

I coded all participant data as necessary and will keep electronic data securely stored on a locked computer for 5 years before deleting. I stored audio files on a computer and interview transcriptions were stored as Microsoft Word files coded and categorized using Microsoft Excel spreadsheets. Reference materials for the study were organized and indexed using Mendeley reference software. Any hard copy documents such as marketing materials or reflective journals will be kept in a securely locked filing cabinet in my office and destroyed after 5 years.

\section{Data Analysis}

Researcher analysis of audio recordings, archival data, and participant observations presents a complex challenge (Kornbluh, 2015; Stuckey, 2014; Sutton \& Austin, 2015). However, qualitative data analysis involves organizing the data into a database, completing an initial read through and note taking, coding the data and 
organizing themes, interpreting the themes from the data, and, presenting the final themes (Mayer, 2015; Stuckey, 2014). Data collection included semistructured interviews, review of marketing strategy documents, and marketing materials from participants' websites and social media sites. I used methodological triangulation for my data analysis process.

Methodological triangulation is the most accurate triangulation method for case study research (Bekhet \& Zauszniewski, 2012). For this study, I analyzed the participant interview data, direct observation data, and marketing strategy materials gathered from participants. I audio-recorded the interviews and had them transcribed by a transcription service into Microsoft Word documents. The audio recordings and Microsoft Word documents were downloaded on my password protected computer hard drive and backed up on my password protected Microsoft OneDrive storage file. I maintained all records of email communication, interview dates and locations using password protected Microsoft Outlook calendar and email. I transcribed the participant information, notes, and researcher reflections during the interviews, as well as important tenets of marketing materials using Microsoft Excel spreadsheets. I stored physical copies of hardcopy archival documents, and any researcher notes, in a locked file cabinet. To properly protect participant information, I coded participant names and any identifying participant information. Coding of participant information is necessary in qualitative research. Researchers use coding to both protect participant information and prevent researcher bias when grouping data to identify themes (Chowdhury, 2015; Gheondea-Eladi, 2014; 
Stuckey, 2014). I will store all records for 5 years from study completion before destroying.

Initially, I compiled all the data into a Microsoft Excel database and then disassemble the compiled data into categories. My initial theme identification approach was to categorize the evidence related to each interview question first. Qualitative case study researchers may initially categorize data from interview questions by the answer to each question (Belk, 2017; Yin, 2014). Yin also suggested once the data is categorized to place the evidence within each category and then create data displays such as flowcharts to assist in researcher examination of the data. I used memos, notes, flowcharts and categorizing of data to triangulate the data to establish themes by category initially. After reassessing identified categories, I used NVivo 12 to compare my initial categories to the NVivo generated themes.

I used a qualitative data analysis software called NVivo 12 to assist me with data analysis. Researchers can use computer-assisted qualitative data analysis software as a reliable tool for data analysis (Chandra \& Shang, 2017; Derobertmasure \& Robertson, 2014; Yin, 2014). Although software such as NVivo 12 is no replacement for the researcher in the coding process, utilization of NVivo 12 can significantly decrease the time a researcher takes to categorize themes (Chandra \& Shang, 2017; M. Oliveira, Bitencourt, dos Santos, \& Teixeira, 2015). However, a researcher should not blindly accept identified themes without challenge. A qualitative researcher will question the 
meaning of the reoccurring concepts and ideas to identify the themes (McCormack, Schnee, \& VanOra, 2014; Ryan \& Bernard, 2003).

\section{Reliability and Validity}

\section{Reliability}

A qualitative researcher creates dependability in a study by adhering to rigorous methods. Reliability is the degree to which study methodology will provide the same results if the underlying phenomenon remains unchanged (Ryan \& Bernard, 2003; Yin, 2014). Chowdhury (2015) proposed the social nature of qualitative research does not allow computer software to objectify the ambiguous nature of the data. However, the researcher can create reliability through clear direction and rationale of methodology

(Chowdhury, 2015; McCormack et al., 2014). Coding, member checks, peer review, and triangulation ensure dependability. I enhanced the reliability of my study by following the guidelines set forth by qualitative researchers including transcript review, member checking of data interpretation, use of an interview protocol including researcher reflections. Yin (2014) suggested an interview protocol improves the reliability of case studies. I used an interview protocol to provide structure and reliability of the data collected during participant interviews. Brawley and Pury (2014) supported the use of additional detail and reflection recording during interviews to aid the reliability of observational data collection. During the interview, I used an interview detail and researcher reflections recording sheet to document observed details at the moment, while audio recording the interview. 
I also improved dependability and credibility for this study by applying triangulation to my data collection methods. Triangulation of data allows the researcher to present a complete and accurate participant account by comparison of different perspectives of the same phenomenon (Chowdhury, 2015; Cox, 2007; Franco et al. 2014; Hyett et al., 2014). I gathered data using several sources including hard copy company marketing materials, social media marking posts, and semistructured interviews to enhance the dependability of the findings.

\section{Validity}

In qualitative research, validity is related to the credibility, transferability, and confirmability of the study findings (Abdalla, Oliveira, Azevedo, \& Gonzalez, 2018; Anney, 2014; Yin, 2013). Credibility is a form of internal validity for qualitative research. These criteria relate to how believable the study results are since no statistical tests for validity in qualitative research exist (Sutton \& Austin, 2015). I used a digital audio recorder for participant interviews and data collection. An audio recording of participant interviews ensures important details are not forgotten when transcribing the interview and can mitigate researcher biases within interview notetaking (Belk, 2017; Sutton \& Austin, 2015; Yates \& Leggett, 2016). Moreover, the interviews will be semistructured, aiding in study credibility (Birt et al., 2016). A researcher can use member checking steps, including participant transcript review and software theme identification, to demonstrate the researcher is addressing study findings from the participant perspective (Abdalla et al., 2018; Birt et al., 2016). After the interviews were 
recorded, I hired a third-party vendor to transcribe them. I then sent the transcribed interview to the corresponding participant for transcription review as part of the member checking process. After making any corrections on behalf of the participants, I processed the transcription data using NVivo to identify the themes of the interview data.

Triangulation of multiple data sources is a method that qualitative researchers use to enhance confirmability. Findings based on evidence attained from interviews, participant observation, and company documents are more convincing than findings based on one or two sources (Abdalla et al., 2018; Anney, 2014; Gheondea-Eladi, 2014). I conducted participant interviews, observed participants during the interview, and reviewed company marketing documents and social media advertising posts to ensure adequate triangulation of study data.

Transferability of a study occurs when the results can be generalized to other contexts or future research (Anney, 2014). Anney (2014) proposed that through detailed records and purposive sampling, transferability of results is created. I chose appropriate participants for this study and performed extensive data collection and structured data analysis. To further enhance transferability of my study results to future research, I continued to collect study data until data saturation occurred. Qualitative researchers emphasized that data collection should continue until the point of theoretical saturation, when no new information is collected (Brawley \& Pury, 2014). Therefore, while collecting data, the researcher will simultaneously identify themes through field notes and journals and compare them with incoming data to determine when diminished returns of 
new information have occurred and repetition of data is sufficient (Brawley \& Pury, 2014; Mayer, 2015). When themes overlapped consistently, I achieved data saturation and stopped collecting new data.

\section{Transition and Summary}

The purpose of this study was to explore the marketing strategies that owners of successful small physical therapy practices have used to retain their businesses for 5 years of operation. Section 2 included the purpose of the study, the role of the researcher, study participant description, and the research method and design. Section 2 also included population and sampling methods, ethical research, data collection instruments and technique, data organization techniques, as well as a discussion of data analysis, reliability, and validity. In Section 3, I presented the finding, the application of the findings to professional practice, and the implications for social change. Lastly, I revealed my recommendations for action and future research, my reflections, and, conclusion. 
Section 3: Application to Professional Practice and Implications for Change Introduction

The purpose of this qualitative multiple case study was to explore marketing strategies physical therapy practice owners use to sustain their businesses beyond 5 years of operation. The data came from my interviews with five successful physical therapy small business owners and my review of marketing strategy documents and Internet marketing examples used by these owners whose businesses were in northeast Florida. I used methodological triangulation of all data sources to identify themes including interview data, marketing strategy documents, online website data, and social media marketing examples. The participants validated marketing strategies consistent with Aaker's (1991) brand equity model and review of the professional literature. The findings showed marketing strategies that small business owners used to sustain their businesses include creating brand awareness, relationship marketing, perceived quality, social media and online marketing, and WOM marketing.

\section{Presentation of the Findings}

The overarching research question for this study was what are the marketing strategies that small business owners use to sustain their business? I interviewed five participants that own a small physical therapy practice over a 5-week period utilizing semistructured interviews that lasted approximately 30 minutes. Each participant answered nine open-ended questions about marketing strategies and business 
sustainability. Additional study data came from participant provided marketing materials and online marketing examples such as social media posts and company websites.

I followed the theme development process by Vaismoradi, Jones, Turunen, and Snelgrove (2016). This approach included four phases of the theme development process: (a) initialization, (b) construction, (c) rectification, and (d) finalization (Vaismoradi et al., 2016). The initialization phase initially consisted of reading transcripts and highlighting meaningful sections. Next, I used the interview questions to outline and classify the meaningful sections and categorize them by interview question. Then I reread the interview transcripts and compared participant answers to each interview question. The second phase of theme development is construction (Vaismoradi et al., 2016). During the construction phase I defined and described labels of highlighted information in my research journal while both immersing myself in the data and maintaining objective distance through bracketing techniques (Sorsa et al., 2015). The third phase of theme development is rectification. During this phase a focused the themes down to five common themes and related them to the established body of knowledge on small business marketing strategies and the conceptual framework. In the finalization phase of theme development, I used my written commentary to connect the themes to answer the study research question.

\section{Theme 1: Brand Awareness}

Brand awareness was a marketing strategy used by all participants. Brand awareness is the potential customer's ability to recall a brand is a member of its market 
category (Girard et al., 2017). Aaker (1991) proposed that brand awareness involves a range of consumer recognition from uncertainty the brand exists, to the belief that it is the only brand in the product class. An example of total brand awareness at the highest level is when the brand becomes synonymous with the service class. For example, if a consumer calls all independent ride sharing services Uber, the consumer would believe Uber is the only ride sharing service.

Physical therapy is a profession with poor consumer awareness. For example, direct access to physical therapy services occurs in the United States yet; most patients believe a physician examination is necessary to diagnose their musculoskeletal problem (Riley, Tafuto, \& Brismée, 2016). Unfortunately, consumers are not aware of the improved outcomes and decreased costs associated with going directly to a physical therapy provider first. Ohja, Snyder, and Davenport (2014) held that physical therapy by direct access compared with physician referred episodes of care was related to improved service outcomes and fewer payer costs.

Four participants discussed ways they market directly to the consumer through community involvement (see Table 1). All five participants spoke to the need for establishing brand awareness through various methods. Participant 1 described community events such as fundraisers and $5 \mathrm{k}$ races that get their brand name on a t-shirt and improve community awareness. Participant 1 stated, "Getting involved with community events is huge in a town like ours. It's really important to get involved out in the community. Get your name out there." 
Table 1

Coding of Participants' Responses Related to Themes

\begin{tabular}{lcc}
\hline \multicolumn{1}{c}{ Themes } & Participants $^{\mathrm{a}}$ & Responses $^{\mathrm{b}}$ \\
\hline Brand awareness & 5 & 20 \\
Relationship Marketing & 5 & 12 \\
Perceived Service Quality & 5 & 18 \\
Social Media and Online Marketing & 4 & 19 \\
Word-of-Mouth Marketing & 5 & 15 \\
\hline
\end{tabular}

Note. ${ }^{\mathrm{a}}$ Number of participants whose interview answer matched the theme. ${ }^{\mathrm{b}}$ Number of participant responses linked to the themes.

Four of the five participants improved brand awareness through free community workshops such as back school and worksite ergonomic instruction. During the time of Facebook post sampling, three of the participants had mention of community events they would be offering or participating in. Two participants provided marketing handouts such as flyers, stress balls with logos and T-shirts that they hand out during these community events. Participant 2 discussed having every new physical therapist he or she hires host workshops in their practice and attend to their free screening tent station at running races and local community events. When asked how he or she creates brand awareness, Participant 2 said:

So, getting our name out there and educating through workshops that we do, free workshops. When I bring on new PTs, [community events] is what has worked best for them...getting themselves out in the community, and having people, know who they are and what they do. 
The brand equity model, places brand association in connection to the brand anchoring effect. Anchoring is a judgment on a stimulus based on assessment of another stimulus with insufficient recalibration away from the initial judgment (Esch et al., 2009; Koll \& von Wallpach, 2014). When a consumer forms an impression about a brand due to exposure with brand through an alternative stimulus, such as community involvement, positive anchoring can occur. All participants were using anchoring to maximize brand associations through community involvement and workshops. For example, if a clinic specializes in back pain management, they may more specifically cause a brand anchoring effect by hosting a free low back pain workshop. This specific brand anchoring effect of brand awareness marketing strategy will likely ensure a stronger bond in the consumers mind to the specialization offered by the brand (Chen et al., 2015; Esch et al., 2009).

\section{Theme 2: Relationship Marketing}

Relationship marketing applies to two distinct entities in physical therapy practice. Firstly, the therapeutic alliance between a physical therapist and their patient can be considered. This relationship needs to be maintained not only for a current dose of rehabilitation but to ensure future units of care (Chahal \& Bala, 2017). The second relationship marketing entity is the relationship between the physical therapy business owner and the referral source. Although all states within the US allow some form of direct access, some third-party payers require a referral from other health care 
practitioners such as medical doctors. Maintaining a healthy and open relationship with referral sources is important for future business interactions.

Initially, the relationship with the referral source is where most participants focused their early efforts. When patients do not go directly to a physical therapist and instead see a physician, physicians are not always referring patients to physical therapy appropriately. In actuality, the likelihood of general practitioners referring patients to physical therapy is low for most musculoskeletal health problems (Dennis et al., 2018). All participants reported efforts to maintain a relationship with referring physicians to minimize this occurrence. The participants emphasized the importance of early relationship and communication development with their referral source during their first 5 years of operation. Participant 3 would send thank-you notes, hosted luncheons, brought coffee, and major holiday cards to referral source offices. These holiday cards included pictures of his family to add a personal touch.

As the participant owners noticed their clinics became stable with patient caseload from referral souces, the participants shifted marketing focus to a greater emphasis on their relationship with current patients. However, all participants emphasized the importance of referral source marketing in the initial 5 years after starting. Participant 5 stated:

Other businesses might be different. But it seems like during the first 5 years I was doing a lot more marketing with the lunches and that type of stuff, than now. You find out who your good referral sources are, and you find out the ones that 
are hit or miss...for the ones that you've build up the relationship with, you just keep on building that relationship.

Additionally, Participant 3 reported, "Early on...there were some nights where I was up till midnight cooking a meal for some small office. I would do personal meals, some took total advantage of it, while others were very appreciative."

Participant 1 had a specific method of building rapport with the entire front office staff. He or she keeps a note book with personal details of each front office manager for each referral source. Before each visit Participant 1 reviews the details and can communicate with office staff on a personal level. He or she believes this maintains the relationship between visits.

Participant 1 specified:

When you go into a doctor's office to speak to the doctor it's sort of like Fort Knox. The doctors are busy and...they obviously don't want to be bothered. But we always make sure if we can get into see them - because we've developed relationships with them over the years - we never take more than five minutes of their time just to let them know that we've opened a new office, or to let them know that we have a new service.

Participant 3 believed in showing up for office marketing visits dressed in casual medical attire, such as medical scrubs, instead of a more professional dress. Participant 3 thought this made the front office staff more comfortable and easier to relate to. Participant 5 stated he or she had done face-to-face lunches with physicians in the past, but they now 
market more directly with the patients. Participant 5 highlighted the importance of building and maintaining these relationships with physicians and patients. Participant 3 said he or she increases communications with referral sources if he or she ever sense the relationship with the referral source faltering.

All participants used website information or social media postings to foster the relationship between the physical therapist and the patient. Participant 1 uses an informational page on his or her website to describe their clinical environment as one on one care without compromise. In participant 1's practice, the physical therapist and the patient will not be changed during the duration of care to foster a therapeutic alliance. Participant 4 describes his or her mission on their website as individualized treatment with a caring team environment of both patient and other health professionals to optimize outcomes. Facebook postings from participant 5 depict before and after photos of patients with their therapists embracing one another.

Maintaining and enhancing brand loyalty is especially important to small business owners. All of the participant responses and findings for the relationship marketing theme fall within the brand equity model tenant of brand loyalty (Aaker, 1991). A business owner can improve brand loyalty by treating the customer correctly, staying close to the customer through enhanced customer culture, creating switching costs and providing extras (Aaker, 1991). All participants described these brand loyalty tenants in their responses and marketing materials when discussing their relationship marketing strategies with referral sources and patients. 


\section{Theme 3: Perceived Service Quality}

Small business owners should focus on providing exceptional customer service. Yaman (2018) proposed that in today's markets the most important way to sustainability is through good service quality. For services that customers have not yet experienced, they choose high service quality through WOM marketing (Yaman, 2018). Vera (2015) said consumer perceived quality could result in customer willingness to pay a higher price for a service. All participants spoke to the concept of perceived service quality when marketing their business, participant 1 expressed quality of care as the best marketing strategy. He or she stated, "Our best marketing strategy is doing quality care. Patients are very pleased and happy. They come back.” All five participants have different pricing strategies for their services. According to their website and hardcopy marketing pamphlets, the participants advertising low patient volume and high perceived service quality marketing strategies had more expensive service prices.

Sixty percent of participants reported using their marketing materials or slogan to convey the message of high-quality patient service through one on one treatment with a physical therapist to the consumer. The brand equity model included consumer feelings of quality linking to reason to buy and price (Aaker, 1991). When a consumer has subjective feelings that the quality of service is high, he or she has both a reason to choose the service over others and is willing to pay more for that chosen service (Aaker, 1991; Girard et al., 2017; Thi Minh Pham et al., 2016). Participant 1 stated, "When we're treating the patients we treat them like family... when they've left our practice, if they 
have a need to come back and see us in the future, we are at the top of their list." Additionally, Participant 3 answered:

I mean, if you want to call treatment an outcome... it is the absolute best, because then that's what lends itself to the word-of-mouth sharing, that they [our therapists] provide good treatment...that they do work and care for people, and that ends up being the absolute number one tool for getting the word out there. Participant 5 spoke to the quality of care to overcome the threat of larger, hospital-based clinics recent infiltration into the outpatient clinic marketplace. He or she stated, "It really helps having that personal touch [with patients]. Where the bigger companies lose that personal touch, we're able to maintain it. So that's something." Aaker (1991) showed in the brand equity model, that in the service industry achieving high-quality is not enough; actual quality must be translated into perceived quality. Moreover, Aaker observed dimensions of perceived quality in the service context to include competence, reliability, responsiveness, empathy, credibility, trustworthiness, and courtesy.

To deliver high-quality service the firm employees need to commit to quality and the owner needs to foster a quality culture (Aaker, 1991). When Participant 3 was asked if he or she did anything specific to train staff and other company physical therapists to ensure that patients have a consistently high-quality experience, he or she spoke of creating a culture of quality. Participant 3 said, "[The employees] know the environment, the structure and the way that we interact with the patient. And if they don't...or 
something is not done as it should be, it is immediately acted upon and corrected so that it's not reproduced."

Another marketing method all participants expressed was service quality through specialization. In terms the brand equity model, specialization is considered both a reason to buy and a way to differentiate the service in the marketplace (Aaker, 1991; Dwivedi, 2014; Hazée, Van Vaerenbergh, \& Armirotto, 2017). In physical therapy practice, many specializations and specialty certifications are accepted. According to the American Board of Physical Therapy Specialties, the only board certification producing body recognized by the American Physical Therapy Association, nine specialties are offered (American Board of Physical Therapy Specialties, 2018). However, a myriad of nonboard recognized certifications are currently used in physical therapy practice.

All participants felt it is important to offer specialty services, such as certified therapists in these specialty practices to improve service quality. Four of five participants' employed websites with a separate tab to list the specialties they offer and the certifications of their physical therapists. Participant 5 spoke about offering general practice services but also lymphedema and women's health and specified, "You really need to have your niche services that not every clinic is doing". Participant 5 also spoke about niche services allow the clinic to have a specialty market segment that is less competitive making it easier to attract new patients to their clinic.

Even though these are small business physical therapy practices with 1-2 small locations each, the participants have strived to offer diverse physical therapy service 
specializations. Aaker (1991) discussed specialization of services as a subtenant of the perceived quality asset within the brand equity model. Aaker described how perceived quality provides a reason for consumers to purchase and help business owners position the brand in the marketplace. For each practice, all participants used a portion of their website to list specialty services and employee biographies with descriptions of their specialty training (see Table 2). Participant 5 framed his or her clinic's specialization by stating, "The main thing is that niche services help tremendously...we're all fighting for that piece of pie. Those little niche services go a long, long way because now." Using the brand equity model as a conceptual framework, I have presented a relationship between perceived quality marketing and sustainability of small business owners of physical therapy practices that were in business for a minimum of 5 years.

Table 2

Number of Marketed Physical Therapy Specializations

Participant Number $\quad$ Specializations $^{\mathrm{a}}$

\begin{tabular}{ll}
\hline Participant 1 & 10 \\
Participant 2 & 6 \\
Participant 3 & 1 \\
Participant 4 & 6 \\
Participant 5 & 5
\end{tabular}

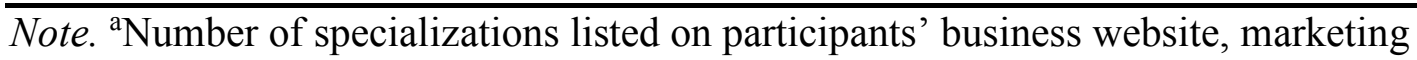
materials, or Facebook page.

\section{Theme 4: Social Media and Online Marketing}

The theme of online marketing through social media and website exposure was common to all participants. Social media marketing currently has unparalleled access to 
potential consumers, and business owners are allocating significant time and funds into social media advertising (Godey et al., 2016; Schivinski et al., 2016; Tanveer, 2017). Despite the current social media business trends, I did notice conflicting findings from participants interviews and the current marketing literature on the effective use of social media marketing. Although all participants were using social media marketing, the degree and frequency of posting were different amongst the participants. All participants answered they used social media to market their business and were able to describe their social media marketing strategies, but the range of utilization was drastic. Participant 1 summed his use of social media and online marketing up in a summary fashion by remarking, "We use more electronic advertising, social media, a website. All of the stuff that wasn't as huge five years ago." Although all participants have company websites and Facebook pages, only $60 \%$ of participants utilized a Twitter business page. Participant 5 offered, "Our main [marketing] is our website. We have a nice website that most patients in the area use...instead of going to a phonebook nowadays everything is mobile and online." Participant 2 had a Twitter business page but did not have a posting in a full month of sampling. Moreover, two participants did not have any Facebook posts during this time of sampling (see Table 3). 
Table 3

Participant Social Media Marketing

\begin{tabular}{lllll}
\hline Participant & Facebook $^{\mathrm{a}}$ Twitter ${ }^{\mathrm{a}}$ Google Reviews Website Link & $\begin{array}{c}\text { Postings per Social Media Site } \\
\text { on Google } \\
\text { Reviews }\end{array}$ \\
& & & & \\
\hline Participant 1 & 4 & 0 & 4 & Yes \\
Participant 2 & 11 & 0 & 15 & Yes \\
Participant 3 & 0 & 0 & 2 & No \\
Participant 4 & 18 & 6 & 59 & Yes \\
Participant 5 & 0 & 6 & 3 & Yes \\
\hline
\end{tabular}

Note. ${ }^{a}$ Time frame of social media sampling was August 1-31, 2018.

I was surprised to learn the low frequency that some participants were posting to social media, including Facebook. Participant 4 was the only participant to hire a marketing consultant to utilize Google Adworks and Facebook business advertising. Participant 4 utilizes automation on Facebook and Google Adworks whereas the other participants were posting manually. Participant 2 reported his online marketing efforts as such, "We ended up finding our best [marketing] results doing as you might expect, social media stuff. A lot of Facebook posts and article sharing on Facebook." Professional management of a Facebook page is correlated to an increased number of page fans which may be leveraged for relationship marketing purposes (Cardoso, Fleury, Feldmann, \& De Araújo, 2017). Raghunath and Fogel (2015) revealed that $67 \%$ of all online users had Facebook accounts in the United States in 2015. With 1.39 billion active users visiting Facebook each month, one could safely assume that there are more Facebook user accounts now than ever before (Tran, 2017). 
Business researchers have linked social media and online reviews as effective methods of WOM marketing. All participants spoke about the value of WOM marketing despite this term not being used in the interview questions, highlighting the participants' high-value beliefs in patient WOM. The range of cumulative Google reviews for their businesses was from 2 to 59 (see Table 3). Kumar et al. (2016) evidenced that social media posts can have a positive influence on consumers likelihood to purchase and Cardoso, Fleury, Feldmann, and Araujo (2017) described the positive relationship between actively managed Facebook pages and number of page fans.

However, it is not outside the scope of the current social media marketing literature for a small business owner to have reservations about social media posting. Some small business owners have trust concerns about online content including social media (Raghupathi \& Fogel, 2015). For less trusted retailers, personalized online advertising can trigger privacy concerns from the user which effects the consumers' click-through intentions (Bleier \& Eisenbeiss, 2015) Additionally; small business owners may question the ethics of using Facebook for marketing purposes. For example, young adult Facebook users are actively engaging with alcohol marketing on Facebook, sometimes without their full comprehension (Niland, McCreanor, Lyons, \& Griffin, 2017). Moreover, a plethora of published peer-reviewed literature including systematic reviews exists, in which researchers have demonstrated relationships between Facebook use and insalubrious mental health domains including Facebook addiction, anxiety, 
depression, envy, body image, and disordered eating, and, alcohol use (Frost \& Rickwood, 2017; Park \& Baek, 2018; Pera, 2018; Twomey \& O’Reilly, 2018).

Overall, Aaker's (1991) brand equity model predates any social media marketing use. However, social media most closely relates to the tenant of brand loyalty. Brand loyalty market can be a method to utilize platforms such as social media, to attract new customers by demonstrating innovation and quality (Aaker, 1991; Finoti, Didonet, Toaldo, \& Martins, 2017). More obviously in relation to the brand equity model, small business owners can use social media to maintain and enhance customer loyalty.

\section{Theme 5: Word-of-Mouth Marketing}

When asked about marketing strategies that attract new patients to their practice, four out of five participants reported effectively using WOM marketing practices. Not surprisingly, when next asked what marketing strategies helped retain current patients, all participants evidenced WOM marketing practices. When asked about using WOM to gain new patients, Participant 3 said, "The patients do it for me, or the physicians do it for me." Participant 1 mentioned WOM as a huge part of their marketing. Participant 2 answered, "Honestly, what I feel is best is that we are establishing a good relationship and good rapport with our patients. They go and tell whoever they deal with what kind of experience they have here." Later Participant 2 added, "But mostly, it's word-of-mouth. It's a small town, so I guess word-of-mouth is best."

WOM has become an influential source of information on consumer intent to purchase. WOM is particularly important in the service industries, including physical 
therapy (Mohtasham, Sarollahi, \& Hamirazavi, 2017). Surprisingly, 80\% of study participants are using traditional WOM marketing pathways and not capitalizing on electronic WOM marketing. King et al. (2014) verified that business owners should encourage satisfied customers to generate high-value electronic WOM, such as customer reviews. Customers left with positive emotions about a service are more likely to spread electronic WOM, so encouraging these reviews are done close to patient discharge may be valuable (Septianto \& Chiew, 2018). Participants discussed the most commonly used formal method of patient WOM was patient testimonials.

One-hundred percent of participants had evidence of patient testimonial marketing on their website or social media site. Participant 2 has patient testimonials on the third tab of the website, which places testimonials before services, specialties, or pricing. Participant 3 has infrequent Facebook posts, but all the posts during the time of inquiry were patient testimonials. Participant 4 highlights selected patient cases at discharge on Facebook one to two times a week with photos and a short patient testimonial. Participant 5 faxes a patient testimonial with the discharge summary back to the medical doctor or referral source after treating the patient. Participant 1 said this when discussing WOM strategies, "So word-of-mouth is huge. We give [patients] promotional items like these things here just to kind of keep our name in front of them." Participant 5 stated, "I feel like the best marketing strategy we utilize is doing good quality care and then having the patients go back and tell us they'd go back and literally tell the doctors about us." 
The brand equity model has brand loyalty and brand awareness as primary tenants. Brand loyalty includes the benefits of reduced marketing costs and attracting new customers (Aaker, 1991). Attracting new customers is directly linked to brand awareness, which can be created by WOM marketing (Aaker, 1991; He, Chen, Lee, Wang, \& Pohlmann, 2017). Aaker (1991) proposed generating brand awareness from the current customer base to attract new customers. WOM attracts new customers by reassuring potential customers of a satisfactory experience. The WOM marketing strategy should use a large satisfied customer base to provide an image of the brand as successful and accepted (Aaker, 1991; Davvetas \& Diamantopoulos, 2016; So, King, Hudson, \& Meng, 2017). Small business owners should realize the value of building a favorable customer interaction over the long-term. A customer base can be taken for granted when the focus is on single service interactions rather than building and maintaining equity.

\section{Applications to Professional Practice}

Based on the study findings, the most significant contribution to professional practice may be the identification of potential marketing strategies physical therapy small business owners use to sustain their businesses beyond 5 years. Franco (2018) discussed the flexible and informal nature of SMEs marketing mix based on common-sense knowledge. The findings of this study support the malleable nature of physical therapy business owners marketing mix. Physical therapy business owners depend on patient treatments for sustainability and to generate profit (Landry et al., 2016). Small business owners can benefit from this study by increasing the likelihood of marketing success and 
a profitable number of patient visits. The use of targeted marketing strategies contributes to a number of new patient referrals and current patient retention. Findings from this study could provide small business leaders with knowledge on how to integrate marketing strategies to sustain their business by attracting new patients, maintaining current patients, and reconnecting with discharged patients through repeat episodes of care.

Considering Franco's (2018) definition of SME networking as the relationship between owners of a SME and the people or organizations they obtain resources and support from, it is clear to see how networking relates to the participant themes. Potential and new physical therapy practice owners may use the findings of this study to understand successful marketing strategies better and understand the importance of these marketing strategies on patient recruitment and retention, thereby enhancing the firms' performance and survival. The results of this study include the following suggestions for physical therapy small business owners using marketing strategies to sustain their business: (a) create community awareness through volunteer activities and workshops to help funnel patient referrals, (b) focus on relationship building with referral sources and current patients, (c) provide excellent services that demonstrate quality and specialization expertise to patients, (d) utilize online marketing tools, (e) emphasize WOM marketing. Building community awareness is a form of creating brand awareness. Creating brand awareness can improve the sales practice, the marketing practice and the communication practice of physical therapy small practice owners. Relationship 
marketing can be the foundation of future business interactions. This model of marketing is particularly important in the service industries including physical therapy practice. Fostering a relationship with referral sources and current patients can aide in patient referrals and patient retention. Providing excellent service and niche expertise can ensure an adequate market share in the service marketplace to enhance brand sustainability and mitigate future marketplace threats. Online marketing tools such as social media platforms are widely used by potential and current physical therapy patients. Small practice physical therapy business owners can use these online platforms to maximize patient marketing exposure. Lastly, WOM marketing can create an image of brand success and entice potential patients to use their services.

\section{Implications for Social Change}

Poor marketing strategies is a potential cause of the failure of over $50 \%$ of small businesses within their first 5 years of operation (Eberhart, Eesley, \& Eisenhardt, 2017; U. S. Small Business Administration, 2014; Zhang, Bessler, \& Leatham, 2013). Through the implementation of successful marketing strategies, in alignment with Aaker's managing brand equity conceptual framework, small physical therapy practice owners could sustain their firm. Comprehending how physical therapy small business owners utilize marketing strategies for sustainability may enable current, and future, small business owners operate their firm effectively. With improved physical therapy practice performance, the company may grow, pay increased corporate taxes, employ local community members, and provide necessary medical services to local inhabitants. 
By utilizing strategies from the findings of this study, physical therapy small business owners may contribute to positive social change by improving the knowledge of future entrepreneurial physical therapy practice owners increasing the number of entrepreneurs and physical therapy practices in the area. Increasing the number and sustainability of physical therapy practices may improve community access and usage of beneficial physical therapy services. The greatest need for physical therapy services is in the areas of chronic pain and musculoskeletal disorders such as low back pain.

In the United States, an opioid epidemic currently exists. More specifically, the distribution of Oxycodone by physicians has increased exponentially in the last 15 years leading to significant patient addiction issues (Mack, Jones, \& McClure, 2017). Physical therapists can help patients modulate their pain intensity and pain experience with the appropriate interventions and therapeutic alliance (Bishop et al., 2015; Fuentes et al., 2014). Low back pain and other musculoskeletal disorders have replaced the common cold as the most cited reason for number of working days missed (Piano et al., 2017). Early and direct access to physical therapy services saves the United States health care expenditure and decreases the number of days off of work for employees. (Carey \& Freburger, 2014; Ohja, Snyder, \& Davenport, 2014; Piano et al., 2017). Less sick days used may mean increased productivity for patients and employers thereby stimulating the growth and sustainability of local community commerce leading to positive social change. 


\section{Recommendations for Action}

The consequences of the poor execution of marketing strategies are meager firm performance and potential failure to survive beyond the first 5 years of operation. (Alon, Boulanger, Misati, \& Madanoglu, 2015; U.S. Small Business Administration, 2016). Based on the five themes identified through methodological triangulation of semistructured interviews, analysis of participant responses, and document review, I recommend the small business owners of physical therapy practices should have adequate business education and training to adopt and annually evaluate the appropriate marketing strategies for sustaining their business.

Physical therapy small business owners generally have minimal formal business training or education before opening their practice. Therefore, gaps exist in the strategic planning and assessment of implemented marketing strategies. Physical therapy small business owners should create, and review marketing strategy plans annually. Physical therapy small business owners could use the 5Ps marketing mix model along with a SWOT analysis as the foundation to develop and revise annual marketing plans (Kash \& Deshmukh, 2013).

Physical therapy small business owners should invest in social media marketing engagement with consumers to extend the relationship marketing behaviors. Electronic WOM is the most widely engaged WOM method, and most participants are not investing enough time or resources in this technique. The return on investment for social media marketing is currently held in high regard (Bianchi \& Andrews, 2018; Jabeur, Nait-Sidi- 
Moh, \& Zeadally, 2018). Young consumers are especially sensitive to brand engagement on social media avenues when deciding to purchase a product or service (Aktaş Arnas, Taș, \& Gürgah Oğul, 2016; Holt, 2016; Sasmita \& Mohd Suki, 2015). I recommend significant investment in social media marketing with an emphasis on popular social media platforms and electronic WOM.

Additionally, physical therapy small business owners should ensure appropriate patient funneling from their community interventions. Sponsorships are intended to trigger consumers positive attitude toward a brand through specific community engagement (Visentin, Scarpi, \& Pizzi, 2016). All participants used community involvement such as free patient workshops, community speaking engagements, and event sponsorships to build brand awareness. However, when interviewing participants, I noticed a lack of direct and strategic marketing funnels for these expenditures of resources.

The Florida Physical Therapy Association and the Private Practice Section of the American Physical Therapy Association are the physical therapy specific agencies that may benefit from this study. The results could be disseminated through these agencies via member email blasts, website editorials, and presented to members of these organizations during regular meetings. Furthermore, I can present the study findings at the annual conferences or local district meetings of the American Physical Therapy Association, the American Academy of Orthopaedic Manual Physical Therapists, and the Florida Physical Therapy Associations. I can share my knowledge on social media sites and through 
publication in physical therapy and academic journals. Lastly, the ProQuest/UMI dissertation database will house a published version of this doctoral study for any interested parties.

\section{Recommendations for Further Research}

I chose a qualitative multiple case study to explore the marketing strategies that five physical therapy small business owners implemented in northeast Florida to sustain their operations for more than 5 years. The study participants produced strategies that matched the literature review and conceptual framework, but researchers could explore some strategies in the future that did not match the literature. Researchers may identify other physical therapy small business practice sustainability strategies and conduct future research on them.

Researchers could explore the cost-effectiveness of physical therapy small business marketing strategies performed via outsourcing. Multiple participants acknowledged marketing consulting companies contacted their firm and offered to handle promotional marketing for their business. Since outsourcing marketing is common in contemporary physical therapy practice, future researchers could compare outsourcing versus not outsourcing marketing strategies to compare the cost-effectiveness of each approach. Additionally, this study was limited to a convenience sampling of five practice owners in northeast Florida. Future researchers could replicate a larger scale study with a random sampling of a greater geographic area (Sutton \& Austin, 2015). These measures would improve the generalizability of the findings across other geographic regions. Time 
is another limitation of this study that future researchers could address. A longer time sampling could ensure the unfolding experience of the participants is fully captured by the investigating researcher (Miller, 2015).

Moreover, as the researcher of this study and a physical therapist, I have an inherent personal bias toward this study and lack of experience. Future researchers who work in an unrelated field will be able to avoid this potential bias (Miyazaki \& Taylor, 2008). I have limited competency in a doctoral research study and consider myself a novice researcher. Novice researchers are more challenged at the qualitative method of organization of participant responses and gaining in-depth comprehension of the themes from the study (Lawrence \& Tar, 2014; Saxena, 2017). I recommend future studies include experienced experts in the field of qualitative research method. These experts could minimize participant bias through careful collection of participant data, ensuring anonymity and respectful handling of data during the publishing process.

\section{Reflections}

Completing this doctoral study was the most difficulty academic experience of my life. Unlike most of my classmates, I completed the Walden University Doctor of Business Administration (DBA) program without a previous masters of business administration (MBA) degree. Not having an MBA made for a steep learning curve at the beginning of the curriculum and initial difficulty completing assignments. As I progressed throughout the program and the doctoral study process I began to see the advantages of not having my MBA. I was able to bring a fresh health science perspective 
to my discussion posts and papers. By overcoming the challenges of this doctoral study process, I feel I grew academically in a way I would not have been able to through a traditional MBA to DBA pathway.

I chose to research marketing strategies for small business owners based on my experience as a physical therapist and my curiosity toward marketing as a specialty area of business practice. My knowledge of marketing and small business practices was enlarged and refined. Additionally, I have a more in-depth and empathetic appreciation for the effort needed to sustain a small physical therapy practice increased.

Finding participants who met the inclusion criteria for this study was difficult; however, the most difficult part was finding a mutually available time to interview participants. Another challenge that I faced during this study was collecting marketing strategy documents. Not all participants could provide any written documentation of a dedicated strategy but were instead, only able to provide an examples of their marketing efforts and verbal explanation of their marketing strategy during the interviews. My understanding of marketing strategies to sustain a physical therapy small business increased because of this study. I am sincerely and forever grateful for the participants' willingness to contribute to the information that formed the research findings.

\section{Conclusion}

Marketing strategies can significantly influence the sustainability of a business. Some physical therapy small business owners lack the marketing strategies needed to sustain their businesses. Aaker's (1991) brand equity model is useful for small business 
owners to examine their current marketing strategy and develop future marketing strategies for their business. Applying the brand equity model, the purpose of this study was to explore marketing strategies that physical therapy small business owners use to sustain their business. The knowledge gained from this study's findings could help other physical therapy practice owners funnel more marketing exploits into new patient referrals and improve current patient retention.

Five small physical therapy practice owners located in northeast Florida participated in interviews and shared documents to explore this subject. After data analysis including methodological triangulation and NVivo 12 software assistance, five themes emerged. The key themes included: (a) creating brand awareness, (b) relationship marketing (c) perceived quality, (d) social media and online marketing, and (e) word-ofmouth marketing. The results of my study align with the evidence in the current literature that small business owners who use marketing strategies to sustain their business are more likely to be successful past the initial 5 years of opening. Utilizing the findings of this study, I confirm that physical therapy small business owners who utilize WOM, brand awareness, perceived quality, and relationship marketing with their current and prospective customers can ultimately sustain their businesses. 


\section{References}

Aaker, D. A. (1991). Managing brand equity. New York, NY: Free Press.

Abdalla, M., Oliveira, L., Azevedo, C., \& Gonzalez, R. (2018). Quality in qualitative organizational research: Types of triangulation as a methodological alternative. Administração: Ensino e Pesquisa, 19, 66-98. https://dx.doi.org/10.13058/raep.2018.v19n1.578

Agnihotri, A. (2013). Turnaround of Harley Davidson - cult brand or strategic fit approach? Journal of Strategic Marketing, 21(3), 292-301. https://dx.doi.org/10.1080/0965254X.2013.768689

Aktaş Arnas, Y., Taş̦, I., \& Gürgah Oğul, İ. (2016). The development of brand awareness in young children: How do young children recognize brands? International Journal of Consumer Studies, 40, 536-542. https://dx.doi.org/10.1111/ijcs.12298

Alford, P., \& Page, S. J. (2015). Marketing technology for adoption by small business. The Service Industries Journal, 35, 655-669. https://dx.doi.org/10.1080/02642069.2015.1062884

Ali Mahdi, H. A., Abbas, M., Mazar, T. Il, \& George, S. (2015). A comparative analysis of strategies and business models of Nike, Inc. and Adidas Group with special reference to competitive advantage in the context of a dynamic and competitive environment. International Journal of Business Management and Economic Research, 6, 167-177. https://dx.doi.org/10.1108/17471111211272129

Alon, I., Boulanger, M., Misati, E., \& Madanoglu, M. (2015). Are the parents to blame? 
Predicting franchisee failure. Competitiveness Review, 25, 205-217.

https://dx.doi.org/10.1108/CR-10-2014-0034

Alshurideh, M. T. (2016). Is customer retention beneficial for customers : A conceptual background. Journal of Research in Marketing, 5, 382-389.

https://dx.doi.org/10.17722/jorm.v5i3.126

American Board of Physical Therapy Specialties. (2018). Specialist certification.

Retrieved from http://www.abpts.org/Certification/

Anney, V. N. (2014). Ensuring the quality of the findings of qualitative research:

Looking at trustworthiness criteria. Journal of Emerging Trends in Educational

Research and Policy Studies, 5, 272-281.

https://dx.doi.org/10.3109/08941939.2012.723954

Atanassova, I., \& Clark, L. (2015). Social media practices in SME marketing activities: A theoretical framework and reserch agenda. Journal of Customer Behaviour, 14, 163183. https://dx.doi.org/10.1362/147539215X14373846805824

Atwong, C. T. (2015). A social media practicum: An action-learning approach to social media marketing and analytics. Marketing Education Review, 25(1), 27-31. https://dx.doi.org/10.1080/10528008.2015.999578

Babatunde, F., Macdermid, J., \& Macintyre, N. (2017). Characteristics of therapeutic alliance in musculoskeletal physiotherapy and occupational therapy practice: A scoping review of the literature. BMC Health Services Research, 17, 1-23. https://dx.doi.org/10.1186/s12913-017-2311-3 
Barnham, C. (2015). Quantitative and qualitative research: Perceptual foundations. International Journal of Market Research, 57, 837-854. https://dx.doi.org/10.2501/IJMR-2015-070

Batra, R., \& Keller, K. L. (2016). Integrating marketing communications: New findings, new lessons, and new ideas. Journal of Marketing, 80, 122-145. https://dx.doi.org/10.1509/jm.15.0419

Bekhet, A., \& Zauszniewski, J. (2012). Methodological triangulation: An approach to understanding data. Nurse Researcher, 20, 40-43. https://dx.doi.org/10.7748/nr2012.11.20.2.40.c9442

Belk, R. W. (2017). Qualitative research in advertising. Journal of Advertising, 46(1), 3647. https://dx.doi.org/10.1080/00913367.2016.1201025

Bennett, R. (2016). Factors contributing to the early failure of small new charity startups. Journal of Small Business and Enterprise Development, 23, 333-348. https://dx.doi.org/10.1108/JSBED-11-2013-0173

Berends, H., Jelinek, M., Reymen, I., \& Stultiëns, R. (2014). Product innovation processes in small firms: Combining entrepreneurial effectuation and managerial causation. Journal of Product Innovation Management, 31, 616-635. https://dx.doi.org/10.1111/jpim.12117

Bianchi, C., \& Andrews, L. (2018). Consumer engagement with retail firms through social media: An empirical study in Chile. International Journal of Retail and Distribution Management, 46, 364-385. https://dx.doi.org/10.1108/IJRDM-02-2017- 
0035

Birt, L., Scott, S., Cavers, D., Campbell, C., \& Walter, F. (2016). Member checking: A tool to enhance trustworthiness or merely a nod to validation? Qualitative Health Research, 26, 1802-1811. https://dx.doi.org/10.1177/1049732316654870

Bishop, M. D., Torres-Cueco, Gay, C., Lluch-Girbés, E., Beneciuk, J. M., \& Bialosky, J. E. (2015). What effect can manual therapy have on a patient's pain experience? Pain Management, 5, 455-464. https://dx.doi.org/10.2217/pmt.15.39

Bleier, A., \& Eisenbeiss, M. (2015). The importance of trust for personalized online advertising. Journal of Retailing, 91, 390-409. https://dx.doi.org/10.1016/j.jretai.2015.04.001

Boyer, S. L., Edmondson, D. R., Baker, B., \& Solomon, P. (2015). Word-of-mouth, traditional and covert marketing: Comparative studies. Academy of Marketing Studies Journal, 19, 102-119. Retrieved from https:/www.abacademies.or.

Brawley, A. M., \& Pury, C. L. (2014). It's like doing a job analysis: You know more about qualitative methods than you may think. Journal of Business and Psychology, 29, 753-760. https://dx.doi.org/10.1007/s10869-014-9372-7

Bromley, E., Mikesell, L., Jones, F., \& Khodyakov, D. (2015). From subject to participant: Ethics and the evolving role of community in health research. American Journal of Public Health, 105, 900-908.

https://dx.doi.org/10.2105/AJPH.2014.302403

Cardoso, M. V., Fleury, F. A., Feldmann, P. R., \& De Araújo, A. C. (2017). Facebook, 
the new grandstand for relationship marketing. BASE - Revista de Administração e Contabilidade Da Unisinos, 14, 108-121.

https://dx.doi.org/10.4013/base.2017.142.03

Carey, T. S., \& Freburger, J. (2014). Physical therapy for low back pain : What is it, and when do we offer it to patients? Annals of Family Medicine, 12, 99-101. https://dx.doi.org/10.1370/afm.1636.P

Carless, D., \& Douglas, K. (2017). Narrative research. The Journal of Positive Psychology, 12, 307-308. https://dx.doi.org/10.1080/17439760.2016.1262611

Chahal, H., \& Bala, R. (2017). Role of customer retention equity in creating and developing brand value. Journal of Relationship Marketing, 16, 119-142. https://dx.doi.org/10.1080/15332667.2016.1242397

Chandra, Y., \& Shang, L. (2017). An RQDA-based constructivist methodology for qualitative research. Qualitative Market Research: An International Journal, 20, 90112. https://dx.doi.org/10.1108/QMR-02-2016-0014

Chatzipanagiotou, K., Veloutsou, C., \& Christodoulides, G. (2016). Decoding the complexity of the consumer-based brand equity process. Journal of Business Research, 69, 5479-5486. https://dx.doi.org/10.1016/j.jbusres.2016.04.159

Chen, Y.-P., Nelson, L. D., \& Hsu, M. (2015). From "where" to "what": Distributed representations of brand associations in the human brain. Journal of Marketing Research, 52, 453-466. https://dx.doi.org/10.1509/jmr.14.0606

Cheung, C. M. K., \& Thadani, D. R. (2012). The impact of electronic word-of-mouth 
communication: A literature analysis and integrative model. Decision Support Systems, 54, 461-470. https://dx.doi.org/10.1016/j.dss.2012.06.008

Chowdhury, M. F. (2015). Coding, sorting and sifting of qualitative data analysis:

Debates and discussion. Quality \& Quantity, 49, 1135-1143.

https://dx.doi.org/10.1007/s11135-014-0039-2

Christensen, N., Black, L., Furze, J., Huhn, K., Vendrely, A., \& Wainwright, S. (2017). Clinical reasoning: Survey of teaching methods, integration, and assessment in entry-level physical therapist academic education. Physical Therapy, 97, 175-186. https://dx.doi.org/10.2522/ptj.20150320

Cichy, J., \& Gradon, W. (2016). Crowdfunding as a mechanism for financing small and medium-sized enterprises. EFinanse: Financial Internet Quarterly, 12, 38-48. https://dx.doi.org/10.14636/1734-039X

Çifci, S., Ekinci, Y., Whyatt, G., Japutra, A., Molinillo, S., \& Siala, H. (2016). A cross validation of consumer-based brand equity models: Driving customer equity in retail brands. Journal of Business Research, 69, 3740-3747. https://dx.doi.org/10.1016/j.jbusres.2015.12.066

Cox, A. M. (2007). Reproducing knowledge: Xerox and the story of knowledge management. Knowledge Management Research and Practice, 5(1), 3-12. https://dx.doi.org/10.1057/palgrave.kmrp.8500118

Creswell, J. W. (2013a). Qualitative inquiry \& research design (3rd ed.). Thousand Oaks, CA: Sage Publications. 
Creswell, J. W. (2013b). Research design: Qualitative, quantitative, and mixed methods approaches (Laureate E). Thousand Oaks, CA: Sage.

Das, R., Jain, K. K., \& Mishra, S. K. (2018). Archival research: A neglected method in organization studies. Benchmarking: An International Journal, 25, 138-155. https://dx.doi.org/10.1108/BIJ-08-2016-0123

Dasgupta, M. (2015). Exploring the relevance of case study research. Vision: The Journal of Business Perspective, 19, 147-160. https://dx.doi.org/10.1177/0972262915575661

Datta, H., Ailawadi, K. L., \& van Heerde, H. J. (2017). How well does consumer-based brand equity align with sales-based brand equity and marketing-mix response? Journal of Marketing, 81(5), 1-20. https://dx.doi.org/10.1509/jm.15.0340

Datta, H., Foubert, B., \& Van Heerde, H. J. (2015). The challenge of retaining customers acquired with free trials. Journal of Marketing Research, 52, 217-234. https://dx.doi.org/10.1509/jmr.12.0160

Davcik, N. S., Vinhas da Silva, R., \& Hair, J. F. (2015). Towards a unified theory of brand equity: Conceptualizations, taxonomy and avenues for future research. Journal of Product \& Brand Management, 24, 3-17. https://dx.doi.org/10.1108/JPBM-6-2014-0639

Davvetas, V., \& Diamantopoulos, A. (2016). "Regretting your brand-self?" The moderating role of consumer-brand identification on consumer responses to purchase regret. Journal of Business Research, 80, 218-227. https://dx.doi.org/10.1016/j.jbusres.2017.04.008 
de Oliveira, M. O. R., Silveira, C. S., \& Luce, F. B. (2015). Brand equity estimation model. Journal of Business Research, 68, 2560-2568. https://dx.doi.org/10.1016/j.jbusres.2015.06.025

DeAngelis, C. D. (2014). Conflicts of interest in medical practice and their costs to the nation's health and health care system. Milbank Quarterly, 92(2), 195-198. https://dx.doi.org/10.1111/1468-0009.12052

Deller, S., \& Conroy, T. (2016). Survival rates of rural businesses: What the evidence tells us. Choices, 31, 1-5. Retrieved from www.choicesmagazine.org.

Dennis, S., Watts, I., Pan, Y., \& Britt, H. (2018). The likelihood of general practitioners referring patients to physiotherapists is low for some health problems: secondary analysis of the Bettering the Evaluation and Care of Health (BEACH) observational study. Journal of Physiotherapy, 64, 178-182.

https://dx.doi.org/10.1016/j.jphys.2018.05.006

Derobertmasure, A., \& Robertson, J. E. (2014). Data analysis in the context of teacher training: Code sequence analysis using QDA Miner®. Quality and Quantity, 48, 2255-2276. https://dx.doi.org/10.1007/s11135-013-9890-9

Dumitrache, V., \& Raileanu-Szeles, M. (2014). The role of business education provided through lifelong learning in enhancing profesional competencies. Evidence from the EU-27 dataset. Amfiteatru Economic, 16, 874-884. Retrieved from http://www.amfiteatruecono.

Dwivedi, A. (2014). Self-brand connection with service brands: Examining relationships 
with performance satisfaction, perceived value, and brand relationship quality. Services Marketing Quarterly, 35, 37-53. https://dx.doi.org/10.1080/15332969.2014.856738

Eberhart, R. N., Eesley, C. E., \& Eisenhardt, K. M. (2017). Failure is an option: Institutional change, entrepreneurial risk, and new firm growth. Organization Science, 28, 93-112. https://dx.doi.org/10.1287/orsc.2017.1110.

Elbedweihy, A. M., Jayawardhena, C., Elsharnouby, M. H., \& Elsharnouby, T. H. (2016). Customer relationship building: The role of brand attractiveness and consumerbrand identification. Journal of Business Research, 69, 2901-2910. https://dx.doi.org/10.1016/j.jbusres.2015.12.059

Esch, F. R., Schmitt, B. H., Redler, J., \& Langner, T. (2009). The brand anchoring effect: A judgment bias resulting from brand awareness and temporary accessibility. Psychology and Marketing, 26, 383-395. https://dx.doi.org/10.1002/mar.20278 Fatoki, O. (2014). The causes of the failure of new small and medium enterprises in South Africa. Mediterranean Journal of Social Sciences, 5, 922-927. https://dx.doi.org/10.5901/mjss.2014.v5n20p922

Ferreira, P. H., Ferreira, M. L., Maher, C. G., Refshauge, K. M., Latimer, J., \& Adams, R. D. (2013). The therapeutic alliance between clinicians and patients predicts outcome in chronic low back pain. Physical Therapy Journal, 93, 470-478. https://dx.doi.org/10.2522/ptj.20120137

Finoti, L., Didonet, S. R., Toaldo, A. M., \& Martins, T. S. (2017). The role of the 
marketing strategy process in the innovativeness-performance relationship of SMEs. Marketing Intelligence and Planning, 35, 298-315. https://dx.doi.org/10.1108/MIP01-2016-0005

Fjellström, D., \& Guttormsen, D. S. A. (2016). A critical exploration of "access" in qualitative international business field research. Qualitative Research in Organizations and Management: An International Journal, 11, 110-126. https://dx.doi.org/10.1108/QROM-05-2014-1225

Franco, M. (2018). Networking as a marketing tool in small companies: A random and informal approach. Journal of Business Strategy, 39(2), 47-55. https://dx.doi.org/10.1108/JBS-02-2017-0020

Franco, M., Santos, M. D. F., Ramalho, I., \& Nunes, C. (2014). An exploratory study of entrepreneurial marketing in SMEs: The role of the founder-entrepreneur. Journal of Small Business and Enterprise Development, 21(2), 265-283. https://dx.doi.org/10.1108/JSBED-10-2012-0112

Frost, R. L., \& Rickwood, D. J. (2017). A systematic review of the mental health outcomes associated with Facebook use. Computers in Human Behavior, 76, 576600. https://dx.doi.org/10.1016/j.chb.2017.08.001

Fuentes, J., Armijo-Olivo, S., Funabashi, M., Miciak, M., Dick, B., Warren, S., ... Gross, D. P. (2014). Enhanced therapeutic alliance modulates pain intensity and muscle pain sensitivity in patients with chronic low back pain: An experimental controlled study. Physical Therapy, 94, 477-489. https://dx.doi.org/10.2522/ptj.20130118 
Fulgoni, G. M. (2015). How brands using social media ignite marketing and drive growth: Measurement of paid social media appears solid but are the metrics for organic social overstated? Journal of Advertising Research, 55, 232-236. https://dx.doi.org/10.2501/JAR-2015-004

Garbarino, E., \& Lee, O. F. (2003). Dynamic pricing in internet retail: Effects on consumer trust. Psychology \& Marketing, 20, 495-513.

https://dx.doi.org/10.1002/mar.10084

Gardner, J., Samuel, G., \& Williams, C. (2015). Sociology of low expectations: Recalibration as innovation work in biomedicine. Science, Technology \& Human Values, 40, 1-24. https://dx.doi.org/10.1177/0162243915585579

Gensler, S., Valckner, F., Liu-Thompkins, Y., \& Wiertz, C. (2013). Managing brands in the social media environment. Journal of Interactive Marketing, 27, 242-256. https://dx.doi.org/10.1016/j.intmar.2013.09.004

Gheondea-Eladi, A. (2014). Is qualitative research generalizable? Journal of Community Positive Practices, XIV, 114-124. https://dx.doi.org/ISSN 2247-6571

Girard, T., Trapp, P., Pinar, M., Gulsoy, T., \& Boyt, T. E. (2017). Consumer-based brand equity of a private-label brand: Measuring and examining determinants. Journal of Marketing Theory and Practice, 25, 39-56.

https://dx.doi.org/10.1080/10696679.2016.1236662

Godey, B., Manthiou, A., Pederzoli, D., Rokka, J., Aiello, G., Donvito, R., \& Singh, R. (2016). Social media marketing efforts of luxury brands: Influence on brand equity 
and consumer behavior. Journal of Business Research, 69, 5833-5841.

https://dx.doi.org/10.1016/j.jbusres.2016.04.181

Graue, C. (2015). Qualitative data analysis. International Journal of Sales, Retailing \& Marketing, 4(9), 5-15. https://dx.doi.org/10.7903/cmr.14043

Gupta, J., Wilson, N., Gregoriou, A., \& Healy, J. (2014). The value of operating cash flow in modelling credit risk for SMEs. Applied Financial Economics, 24, 649-660. https://dx.doi.org/10.1080/09603107.2014.896979

Hamilton, R. W., Rust, R. T., \& Dev, C. S. (2017). Which features increase customer retention? MIT Sloan Management Review, 58, 79-84. Retrieved from https://sloanreview.mit.edu/.

Hammersley, M. (2016). Reflections on the value of ethnographic re-studies: Learning from the past. International Journal of Social Research Methodology, 19, 537-550. https://dx.doi.org/10.1080/13645579.2015.1056578

Hassan, M., Rafi, A., \& Kazmi, S. S. (2016). Impact of differentiated customer service, brand trust, brand commitment, and brand salience on brand advocacy. International Review of Brand Management and Marketing, 6, 232-238. Retrieved from http://www.econjournals.com.

Hayes, J. P., Chawla, S. K., \& Kathawala, Y. (2015). A comparative study of problems encountered in the development of small businesses in the U.S. and Mexico. Journal of Developing Areas, 49, 395-406. https://dx.doi.org/10.1353/jda.2015.0175

Hazée, S., Van Vaerenbergh, Y., \& Armirotto, V. (2017). Co-creating service recovery 
after service failure: The role of brand equity. Journal of Business Research, 74, 101-109. https://dx.doi.org/10.1016/j.jbusres.2017.01.014

He, Y., Chen, Q., Lee, R. P., Wang, Y., \& Pohlmann, A. (2017). Consumers’ role performance and brand identification: Evidence from a survey and a longitudinal field experiment. Journal of Interactive Marketing, 38(1), 1-11. https://dx.doi.org/10.1016/j.intmar.2016.11.001

Helmich, E., Boerebach, B. C. M., \& Arah, O. A. (2015). Beyond limitations: Improving how we handle uncertainty in health professions education research. Medical Teacher, 37, 1043-1050. https://dx.doi.org/10.3109/0142159X.2015.1073239

Hennig-Thurau, T., Wiertz, C., \& Feldhaus, F. (2015). Does Twitter matter? The impact of microblogging word-of-mouth on consumers' adoption of new movies. Journal of the Academy of Marketing Science, 43, 375-394. https://dx.doi.org/10.1007/s11747014-0388-3

Holt, D. (2016). Branding in the age of social media. Harvard Business Review, (March), 41-50. https://dx.doi.org/10.1353/abr.2012.0147

Hsiao, C. H., Shen, G. C., \& Chao, P. J. (2015). How does brand misconduct affect the brand-customer relationship? Journal of Business Research, 68, 862-866. https://dx.doi.org/10.1016/j.jbusres.2014.11.042

Huang, Y.-S., Hsu, C.-S., \& Ho, J.-W. (2014). Dynamic pricing for fashion goods with partial backlogging. International Journal of Production Research, 52, 4299-4314. https://dx.doi.org/10.1080/00207543.2014.881576 
Hviid, M., \& Shaffer, G. (2012). Optimal low-price guarantees with anchoring. Quantitative Marketing and Economics, 10, 393-417. https://dx.doi.org/10.1007/s11129-012-9121-z

Hyett, N., Kenny, A., \& Dickson-Swift, V. (2014). Methodology or method? A critical review of qualitative case study reports. International Journal of Qualitative Studies on Health and Well-Being, 9, 1-12. https://dx.doi.org/10.3402/qhw.v9.23606

Jabeur, N., Nait-Sidi-Moh, A., \& Zeadally, S. (2018). Crowd social media computing: Applying crowd computing techniques to social media. Applied Soft Computing Journal, 66, 495-505. https://dx.doi.org/10.1016/j.asoc.2017.09.026

Jayamaha, N. P., Wagner, J. P., Grigg, N. P., Campbell-Allen, N. M., \& Harvie, W. (2014). Testing a theoretical model underlying the 'Toyota Way' - An empirical study involving a large global sample of Toyota facilities. International Journal of Production Research, 52, 1-19. https://dx.doi.org/10.1080/00207543.2014.883467

Jayasimha, K. R., Chaudhary, H., \& Chauhan, A. (2017). Investigating consumer advocacy, community usefulness, and brand avoidance. Marketing Intelligence \& Planning, 35, 488-509. https://dx.doi.org/10.1108/MIP-09-2016-0175

Kash, B. A., \& Deshmukh, A. A. (2013). Developing a strategic marketing plan for physical and occupational therapy services: A collaborative project between a critical access hospital and a graduate program in health care management. Health Marketing Quarterly, 30, 263-280.

https://dx.doi.org/10.1080/07359683.2013.814507 
Kasim, A., \& Al-Gahuri, H. A. (2015). Overcoming challenges in qualitative inquiry within a conservative society. Tourism Management, 50, 124-129. https://dx.doi.org/10.1016/j.tourman.2015.01.004

Kaufman, R. (2015). Why your customer service training won't lead to happy customers (or inspired employees). Journal for Quality \& Participation, 37(4), 33-38. Retrieved from www.asq.org/pub/jqp.

Keller, E. (2007). Unleashing the power of word-of-mouth: Creating brand advocacy to drive growth. Journal of Advertising Research, 47, 448-452. https://dx.doi.org/10.2501/S0021849907070468

Kerr, C., Nixon, A., \& Wild, D. (2010). Assessing and demonstrating data saturation in qualitative inquiry supporting patient-reported outcomes research. Expert Review of Pharmacoeconomics \& Outcomes Research, 10, 269-288. https://dx.doi.org/10.1586/erp.10.30

Khalifa, D., \& Shukla, P. (2017). Me, my brand and I: Consumer responses to luxury brand rejection. Journal of Business Research, 81, 156-162. https://dx.doi.org/10.1016/j.jbusres.2017.05.032

Khan, S. (2015). Impact of sources of finance on the growth of SMEs: Evidence from Pakistan. Decision, 42(1), 3-10. https://dx.doi.org/10.1007/s40622-014-0071-z

Kim, D. K., \& Kim, M. (2016). Influence of brand awareness and brand attitude on purchase. Journal of Marketing Thought, 3(1), 16-26. https://dx.doi.org/10.15577/jmt.2016.03.01.3 
King, G., Chao, X., \& Duenyas, I. (2016). Dynamic customer acquisition and retention management. Production and Operations Management, 25, 1332-1343. https://dx.doi.org/10.1111/poms. 12559

King, R. A., Racherla, P., \& Bush, V. D. (2014). What we know and don't know about online word-of-mouth: A review and synthesis of the literature. Journal of Interactive Marketing, 28(3), 167-183.

https://dx.doi.org/10.1016/j.intmar.2014.02.001

Koelsch, L. (2013). Reconceptualizing the member check interview. International Journal of Qualitative Methods, 12(1), 168-179.

https://dx.doi.org/10.1177/1532708611401329

Koll, O., \& von Wallpach, S. (2014). Intended brand associations: Do they really drive consumer response? Journal of Business Research, 67, 1501-1507. https://dx.doi.org/10.1016/j.jbusres.2013.06.010

Koo, W., \& Park, H. (2017). Critical atmospheric cues in designing online stores: The case of Amazon.com. International Journal of Marketing Studies, 9(1), 37-45. https://dx.doi.org/10.5539/ijms.v9n1p37

Kornbluh, M. (2015). Combatting challenges to establishing trustworthiness in qualitative research. Qualitative Research in Psychology, 12, 397-414. https://dx.doi.org/10.1080/14780887.2015.1021941

Krefting, L. (1991). Rigor in qualitative research: The assessment of trustworthiness. The American Journal of Occupational Therapy, 43, 214-222. 
https://dx.doi.org/10.5014/ajot.45.3.214

Kucukemiroglu, S., \& Kara, A. (2015). Online word-of-mouth communication on social networking sites. International Journal of Commerce and Management, 25(1), 2-20. https://dx.doi.org/10.1108/IJCoMA-11-2012-0070

Kumar, A., Bezawada, R., Rishika, R., Janakiraman, R., \& Kannan, P. K. (2016). From social to sale: The effects of firm generated content in social media on customer behavior. Journal of Marketing, 80, 7-25.

https://dx.doi.org/10.1017/CBO9781107415324.004

Kwon, E. (Penny), Ratneshwar, S., \& Thorson, E. (2017). Consumers' social media advocacy behaviors regarding luxury brands: An explanatory framework. Journal of Interactive Advertising, 17, 13-27.

https://dx.doi.org/10.1080/15252019.2017.1315321

Ladeira, C., Cheng, S., \& da Silva, R. (2017). Clinical specialization and adherence to evidence-based practice guidelines for low back pain management: A survey of United States physical therapists. Journal of Orthopaedic \& Sports Physical Therapy, 1, 1-44. https://dx.doi.org/10.2519/jospt.2017.6561

Landry, M. D., Hack, L. M., Coulson, E., Freburger, J., Johnson, M. P., Katz, R., ... Goldstein, M. (2016). Workforce projections 2010-2020: Annual supply and demand forecasting models for physical therapists across the United States. Physical Therapy, 96, 71-80. https://dx.doi.org/10.2522/ptj.20150010

Lawrence, J., \& Tar, U. (2014). The use of grounded theory technique as a practical tool 
for qualitative data collection and analysis. Journal of Travel \& Tourism Marketing, 11(1), 29-40. https://dx.doi.org/10.1080/10548408.2014.883346

Levitt, H. M. (2016). Qualitative methods. In J. C. Norcross, G. R. VandenBos, \& D. K. Freedheim (Eds.), APA handbook of clinical psychology: Theory and research (pp. 335-348). Washington, D.C.: American Psychological Association. https://dx.doi.org/10.1146/annurev-polisci-092415

Liao, S., \& Cheng, C. C. J. (2014). Brand equity and the exacerbating factors of product innovation failure evaluations: A communication effect perspective. Journal of Business Research, 67, 2919-2925. https://dx.doi.org/10.1016/j.jbusres.2012.10.001

Liu, M. T., Wong, I. K. A., Tseng, T. H., Chang, A. W. Y., \& Phau, I. (2017). Applying consumer-based brand equity in luxury hotel branding. Journal of Business Research, 81, 192-202. https://dx.doi.org/10.1016/j.jbusres.2017.06.014

Lund, D. J., \& Marinova, D. (2014). Managing revenue across retail channels: The interplay of service performance and direct marketing, 78(September), 99-118. https://dx.doi.org/10.1509/jm.13.0220.

Ma, V. Y., Chan, L., \& Carruthers, K. J. (2014). Incidence, prevalence, costs, and impact on disability of common conditions requiring rehabilitation in the United States: Stroke, spinal cord injury, traumatic brain injury, multiple sclerosis, osteoarthritis, rheumatoid arthritis, limb loss, and back pa. Archives of Physical Medicine and Rehabilitation, 95, 986-995. https://dx.doi.org/10.1016/j.apmr.2013.10.032

Mack, K. A., Jones, C. M., \& McClure, R. J. (2017). Physician dispensing of Oxycodone 
and other commonly used opioids, 2000-2015, United States. Pain Medicine, 19, 990-996. https://dx.doi.org/10.1093/pm/pnx007

Marshall, B., Cardon, P., Poddar, A., \& Fontenot, R. (2013). Does sample size matter in qualitative research?: A review of qualitative interviews in is research. Journal of Computer Information Systems, 54(1), 11-22.

https://dx.doi.org/10.1080/08874417.2013.11645667

Martí-Parreño, J., Bermejo-Berros, J., \& Aldás-Manzano, J. (2017). Product placement in video games: The effect of brand familiarity and repetition on consumers'memory. Journal of Interactive Marketing, 38, 55-63.

https://dx.doi.org/10.1016/j.intmar.2016.12.001

Mayer, I. (2015). Qualitative research with a focus on qualitative data analysis. International Journal of Sales, Retailing \& Marketing, 4(1), 53-67. Retrieved from https://ijsrm.com.

McCormack, T., Schnee, E., \& VanOra, J. (2014). Researching up: Triangulating qualitative research to influence the public debate of "on-time" college graduation. Teachers College Record, 116(4), 1-35. Retrieved from https://www.tcrecord.org. McCrory, B., Pilcher, N., \& McMillan, J. (2017). A holistic framework to embed good company practice for customer retention. The TQM Journal, 29, 257-275. https://dx.doi.org/10.1108/TQM-11-2015-0139

McIntosh, M., \& Morse, J. (2015). Situating and constructing diversity in semi-structured interviews. Global Qualitative Nursing Research, 2(1), 1-12. 
https://dx.doi.org/10.1177/2333393615597674

Milan, G. S., Eberle, L., \& Bebber, S. (2015). Perceived value, reputation, trust, and switching costs as determinants of customer retention. Journal of Relationship Marketing, 14, 109-123. https://dx.doi.org/10.1080/15332667.2015.1041353

Miller, T. (2015). Going back: 'Stalking', talking and researcher responsibilities in qualitative longitudinal research. International Journal of Social Research Methodology, 18, 293-305. https://dx.doi.org/10.1080/13645579.2015.1017902

Min, S., Zhang, X., Kim, N., \& Srivastava, R. K. (2016). Customer acquisition and retention spending: An analytical model and empirical investigation in wireless telecommunications markets. Journal of Marketing Research, 53, 728-744. https://dx.doi.org/10.1509/jmr.14.0170

Miyazaki, A. D., \& Taylor, K. A. (2008). Researcher interaction biases and business ethics research: Respondent reactions to researcher characteristics. Journal of Business Ethics, 81, 779-795. https://dx.doi.org/10.1007/s10551-007-9547-5

Mohtasham, S. S., Sarollahi, S. K., \& Hamirazavi, D. (2017). The effect of service quality and innovation on word-of-mouth marketing success. Eurasian Business Review, 7, 229-245. https://dx.doi.org/10.1007/s40821-017-0080-x

Mollick, E. (2014). The dynamics of crowdfunding: An exploratory study. Journal of Business Venturing, 29(1), 1-16. https://dx.doi.org/10.1016/j.jbusvent.2013.06.005 Mou, J., \& Shin, D. (2018). Effects of social popularity and time scarcity on online consumer behaviour regarding smart healthcare products: An eye-tracking approach. 
Computers in Human Behavior, 78(1), 74-89.

https://dx.doi.org/10.1016/j.chb.2017.08.049

Mukherjee, S., \& Shivani, S. (2016). Marketing mix influence on service brand equity and its dimensions. Vision: The Journal of Business Perspective, 20(1), 9-23. https://dx.doi.org/10.1177/0972262916628936

Newman, G. E., \& Dhar, R. (2014). Authenticity is contagious: Brand essence and the original source of production. Journal of Marketing Research, 51, 371-386. https://dx.doi.org/10.1509/jmr.11.0022

Niland, P., McCreanor, T., Lyons, A. C., \& Griffin, C. (2017). Alcohol marketing on social media: Young adults engage with alcohol marketing on Facebook. Addiction Research \& Theory, 25, 273-284.

https://dx.doi.org/10.1080/16066359.2016.1245293

Ohja, H., Snyder, R., \& Davenport, T. (2014). Direct access compared with referred physical therapy episodes of care: A systematic review. Physical Therapy, 94, 1430. https://dx.doi.org/10.1136/jech.2003.008490

Oliveira, M., Bitencourt, C., dos Santos, A., \& Teixeira, E. (2010). Thematic content analysis: Is there a difference between the support provided by the MAXQDA and NVivo software packages? IV Encontro de Marketing Da ANPAD, 9, 1-17. https://dx.doi.org/10.5902/19834659

Opuni, F., Asiedu, K., \& Acheampong, I. (2014). The effect of celebrity endorsement on product purchase: The case of fan milk, fan yogo, specialized mineral water and root 
extra beer. International Journal of Global Business, 53(12), 34-56.

https://dx.doi.org/10.1017/CBO9781107415324.004

Park, J., \& Park, M. (2016). Qualitative versus quantitative research methods: Discovery or justification? Journal of Marketing Thought, 3(10), 1-7. https://dx.doi.org/10.15577/jmt.2016.03.01.1

Park, S. Y., \& Baek, Y. M. (2018). Two faces of social comparison on Facebook: The interplay between social comparison orientation, emotions, and psychological wellbeing. Computers in Human Behavior, 79, 83-93.

https://dx.doi.org/10.1016/j.chb.2017.10.028

Patterson, S., \& Malpass, F. (2015). The influence of Bill Schlackman on qualitative research. International Journal of Market Research, 57, 677-700. https://dx.doi.org/10.2501/IJMR-2015-058

Pera, A. (2018). Psychopathological processes involved in social comparison, depression, and envy on Facebook. Frontiers in Psychology, 9(22), 1-5. https://dx.doi.org/10.3389/fpsyg.2018.00022

Peterson, A. E., Bond, G. R., Drake, R. E., McHugo, G. J., Jones, A. M., \& Williams, J. R. (2014). Predicting the long-term sustainability of evidence-based practices in mental health care: An 8-year longitudinal analysis. Journal of Behavioral Health Services and Research, 41, 337-346. https://dx.doi.org/10.1007/s11414-013-9347-x

Piano, L., Maselli, F., Viceconti, A., Gianola, S., \& Ciuro, A. (2017). Direct access to physical therapy for the patient with musculoskeletal disorders, a literature review. 
Journal of Physical Therapy Science, 29, 1463-1471.

https://dx.doi.org/10.1589/jpts.29.1463

Raghupathi, V., \& Fogel, J. (2015). The impact of opinion leadership on purchases through social networking websites. Journal of Theoretical and Applied Electronic Commerce Research, 10(3), 18-29. https://dx.doi.org/10.4067/S071818762015000300003

Ranjan Dash, S., \& Mahakud, J. (2013). Conditional multifactor asset pricing model and market anomalies. Journal of Indian Business Research, 5, 271-294. https://dx.doi.org/10.1108/JIBR-12-2012-0126

Reinecke, J., Arnold, D. G., \& Palazzo, G. (2016). Qualitative methods in business ethics, corporate responsibility, and sustainability research. Business Ethics Quarterly, 26, xiii-xxii. https://dx.doi.org/10.1017/beq.2016.67

Riley, S. P., Tafuto, V., \& Brismée, J. M. (2016). Retrospective analysis of physical therapy utilization by the specificity of the diagnosis and order written on the referral. Physiotherapy Theory and Practice, 32, 461-467. https://dx.doi.org/10.3109/09593985.2016.1145310

Rogers, W., \& Lange, M. M. (2013). Rethinking the vulnerability of minority populations in research. American Journal of Public Health, 103, 2141-2146.

https://dx.doi.org/10.2105/AJPH.2012.301200

Rundle, R., Roberts, J., Whitney, G., Mankins, S., Dille, C., Donaldson, M., \& Hassen, A. (2016). A comparison between civilian and military physical therapists' 
knowledge in managing musculoskeletal conditions: A descriptive study. International Journal of Sports Physical Therapy, 11(1), 115-125. Retrieved from https:/ifspt.org/education/journals/

Runfola, A., Perna, A., Baraldi, E., \& Gregori, G. L. (2017). The use of qualitative case studies in top business and management journals: A quantitative analysis of recent patterns. European Management Journal, 35(1), 116-127.

https://dx.doi.org/10.1016/j.emj.2016.04.001

Ryan, G. W., \& Bernard, H. R. (2003). Techniques to identify themes. Field Methods, 15, 85-109. https://dx.doi.org/10.1177/1525822X02239569

Sahni, S., Rana, A., \& Talwar, S. (2015). Practical matters: The ABC's of better medical practice management. Medical Economics, May, 56-58. Retrieved from https://medicaleconomics.mod.

Sasmita, J., \& Mohd Suki, N. (2015). Young consumers' insights on brand equity: Effects of brand association, brand loyalty, brand awareness, and brand image. International Journal of Retail and Distribution Management, 43, 276-292. https://dx.doi.org/10.1108/IJRDM-02-2014-0024

Saxena, R. (2017). Muddling through the passage of qualitative research: Experiences of a novice researcher. Vision, 21, 314-322. https://dx.doi.org/10.1177/0972262917721423

Sayre, J. W., Toklu, H. Z., Ye, F., Mazza, J., \& Yale, S. (2017). Case reports, case series - From clinical practice to evidence-based medicine in graduate medical education. 
Cureus, 9(8), 7-11. https://dx.doi.org/10.7759/cureus.1546

Schivinski, B., Christodoulides, G., \& Dabrowski, D. (2016). Measuring consumers engagement with brand related social media content. Journal of Advertising Research, 56(1), 1-18. https://dx.doi.org/10.2501/JAR-2016-000

Septianto, F., \& Chiew, T. M. (2018). The effects of different, discrete positive emotions on electronic word-of-mouth. Journal of Retailing and Consumer Services, 44(5), 110. https://dx.doi.org/10.1016/j.jretconser.2018.05.006

Šerić, M., Gil-Saura, I., \& Mikulić, J. (2017). Customer-based brand equity building. Journal of Vacation Marketing, 23(2), 133-144. https://dx.doi.org/10.1177/1356766716634151

Sloan, C. (2015). Neuroeconomics and neuromarketing. International Journal of Business Management and Economic Research, 6(2), 133-136. Retrieved from http://ijbmer.com.

Smith, J. (2015). How health care marketers can isolate advertising's role in changing consumer behavior. Marketing Health Services, 35(4), 16-21. https://dx.doi.org/10.1017/CBO9781107415324.004

So, K. K. F., King, C., Hudson, S., \& Meng, F. (2017). The missing link in building customer brand identification: The role of brand attractiveness. Tourism Management, 59, 640-651. https://dx.doi.org/10.1016/j.tourman.2016.09.013

Sorsa, M. A., Kiikkala, I., \& Astedt-Kurki, P. (2015). Bracketing as a skill in conducting unstructured qualitative interviews. Nurse Researcher, 22(4), 8-12. 
https://dx.doi.org/10.7748/nr.22.4.8.e1317

Staller, K. M. (2015a). Moving beyond description in qualitative analysis: Finding applied advice. Qualitative Social Work: Research and Practice, 14, 731-740. https://dx.doi.org/10.1177/1473325015612859

Staller, K. M. (2015b). Qualitative analysis: The art of building bridging relationships. Qualitative Social Work, 14(2), 145-153. https://dx.doi.org/10.1177/1473325015571210

Staniewski, M. W., Szopiński, T., \& Awruk, K. (2016). Setting up a business and funding sources. Journal of Business Research, 69, 2108-2112. https://dx.doi.org/10.1016/j.jbusres.2015.12.016

Stuckey, H. (2014). The first step in data analysis: Coding qualitative research data. Journal of Social Health and Diabetes, 2(1), 6-10. https://dx.doi.org/10.4103/23210656.120254

Styles, C., \& Goddard, J. (2014). Spinning the wheel of strategic innovation. Business Strategy Review, 25, 76-80. https://dx.doi.org/10.1111/j.1467-8616.2014.01130.x

Sullivan, D. M., \& Ford, C. M. (2014). How entrepreneurs use networks to address changing resource requirements during early venture development. Entrepreneurship Theory and Practice, 38, 551-574.

https://dx.doi.org/10.1111/etap.12009

Sutton, J., \& Austin, Z. (2015). Qualitative research: Data collection, analysis, and management. The Canadian Journal of Hospital Pharmacy, 68, 226-231. 
https://dx.doi.org/10.1111/acem.12735

Tălpău, A. (2014). The marketing mix in the online environment. Bulletin of the Transylvania University, 7(2), 53-58. https://dx.doi.org/10.1057/9781137488961.0010

Tamaddoni, A., Stakhovych, S., \& Ewing, M. (2017). The impact of personalised incentives on the profitability of customer retention campaigns. Journal of Marketing Management, 33, 327-347.

https://dx.doi.org/10.1080/0267257X.2017.1295094

Tanveer, N. (2017). Social media: The new frontier for pathologists. Indian Journal of Pathology \& Microbiology, 60, 143-144. https://dx.doi.org/10.4103/03774929.200041

Tennert, F. (2014). An attributional analysis of corporate reporting in crisis situations: The 2010 Toyota recall. Journal of Communication Management, 18, 422-435. https://dx.doi.org/10.1108/JCOM-09-2012-0074

Thi Minh Pham, L., Nga Do, H., \& Minh Phung, T. (2016). The effect of brand equity and perceived value on customer revisit intention: A study in quick-service restaurants in Vietnam. Acta Oeconomica Pragensia, 24(5), 14-30. https://dx.doi.org/10.18267/j.aop.555

Torres, J. P., \& Kunc, M. H. (2016). Market opportunity recognition in the Chilean wine industry: Traditional versus relational marketing approaches. Journal of Wine Research, 27(1), 19-33. https://dx.doi.org/10.1080/09571264.2016.1144584 
Tran, T. P. (2017). Personalized ads on Facebook: An effective marketing tool for online marketers. Journal of Retailing and Consumer Services, 39, 230-242. https://dx.doi.org/10.1016/j.jretconser.2017.06.010

Twomey, C., \& O'Reilly, G. (2018). The association of 'self-monitoring' with depression in help-seeking Facebook users. International Journal of Social Psychiatry, 64, 482487. https://dx.doi.org/10.1177/0020764018778700

U. S. Small Business Administration. (2014). Frequently asked questions about small businesses.

U.S. Small Business Administration. (2014). Survival rates and firm age.

U.S. Small Business Administration. (2015a). Small business profile: Florida, 1-4.

U.S. Small Business Administration. (2015b). Small business profiles for the states and territories, (February), 1-2.

U.S. Small Business Administration. (2016). State business profiles: Florida, 41-44.

Vaismoradi, M., Jones, J., Turunen, H., \& Snelgrove, S. (2016). Theme development in qualitative content analysis and thematic analysis. Journal of Nursing Education and Practice, 6, 100-110. https://dx.doi.org/10.5430/jnep.v6n5p100

Valančienè, L., \& Jegelevičiūtè, S. (2013). Valuation of crowdfunding: Benefits and drawbacks. Economics and Management, 18(1), 39-49.

https://dx.doi.org/10.5755/j01.em.18.1.3713

Van Den Berg, A., \& Struwig, M. (2017). Guidelines for researchers using an adapted consensual qualitative research approach in management research. The Electronic 
Journal of Business Research Methods, 15(2), 109-119.

Van Noort, G., Antheunis, M. L., \& Verlegh, P. W. J. (2014). Enhancing the effects of social network site marketing campaigns: If you want consumers to like you, ask them about themselves. International Journal of Advertising, 33, 235-253.

https://dx.doi.org/10.2501/IJA-33-2-235-252

Venkatesh, V., Brown, S. A., \& Sullivan, Y. (2016). Guidelines for conducting mixedmethods research: An extension and illustration. Journal of the Association for Information Systems, 17, 435-495. https://dx.doi.org/Retrieved from http://aisel.aisnet.org

Vera, J. (2015). Perceived brand quality as a way to superior customer perceived value crossing by moderating effects. Journal of Product \& Brand Management, 24(2), 147-156. https://dx.doi.org/10.1108/JPBM-04-2014-0551

Visentin, M., Scarpi, D., \& Pizzi, G. (2016). From assessment to purchase: A three-stage model of the marketing funnel in sponsorship activities. Journal of Sport Management, 30, 615-628. https://dx.doi.org/10.1123/jsm.2015-0358

Vitak, J., Shilton, K., \& Ashktorab, Z. (2016). Beyond the Belmont Principles: Ethical challenges, practices, and beliefs in the online data research community. In Proceedings of the 19th ACM Conference on Computer-Supported Cooperative Work \& Social Computing (pp. 939-951). San Francisco, CA. https://dx.doi.org/10.1145/2818048.2820078

Wendler, D., \& Abdoler, E. (2010). Does it matter whether investigators intend to benefit 
research subjects? Kennedy Institute of Ethics Journal, 20, 353-370. Retrieved from http://www.ncbi.nlm.nih.go.

Wilburn, K. M., \& Wilburn, H. R. (2016). Asking “What Else?” to identify unintended negative consequences. Business Horizons, 59, 213-221. https://dx.doi.org/10.1016/j.bushor.2015.11.006

Xie, K., \& Lee, Y. (2014). Quantifying the impact of earned and owned social media exposures in a two-stage decision making model of brand purchase. Journal of Management Information Systems, 32, 204-238. https://dx.doi.org/10.1080/07421222.2015.1063297

Yaman, Z. (2018). The effect of word-of-mouth marketıng on the purchase behavior via brand image and perceived quality. Montenegrin Journal of Economics, 14, 175182. https://dx.doi.org/10.14254/1800-5845/2018.14-2.12

Yates, J., \& Leggett, T. (2016). Qualitative research: An introduction. Radiologic Technology, 88, 225-231. Retrieved from https://www.radiologictech.

Yaya, L. H. P., Fortià, M. F., Canals, C. S., \& Marimon, F. (2015). Service quality assessment of public transport and the implication role of demographic characteristics. Public Transport, 7, 409-428. https://dx.doi.org/10.1007/s12469014-0099-7

Yin, R. K. (2013). Validity and generalization in future case study evaluations. Evaluation, 19, 321-332. https://dx.doi.org/10.1177/1356389013497081 Yin, R. K. (2014). Case study research: Design and methods (5th ed.). Thousand Oaks, 
CA: Sage Publications.

Yurdakul, D., Atik, D., \& Dholakia, N. (2017). Redefining the bottom of the pyramid from a marketing perspective. Marketing Theory, 17, 289-303. https://dx.doi.org/10.1177/1470593117704265

Zarantonello, L., Schmitt, B. H., \& Jedidi, K. (2014). How to advertise and build brand knowledge globally: Comparing television advertising appeals across developed and emerging economies. Journal of Advertising Research, 54, 420-434. https://dx.doi.org/10.2501/JAR-54-4-420-434

Zhang, J., Bessler, D. A., \& Leatham, D. J. (2013). Aggregate business failures and macroeconomic conditions: A var look at the U.S. between 1980 and 2004. Journal of Applied Economics, 16(1), 179-202. https://dx.doi.org/10.1016/S1514$0326(13) 60008-2$

Zinkhan, G. E. (2002). Relationship marketing: Theory and implementation. Journal of Market-Focused Management, 5(1), 83-89.

https://dx.doi.org/10.1023/A:1014031025271 
Appendix A: Semistructured Interview Protocol

I will use the following interview protocol:

1. Once receipt of the invitation to participate and informed consent email from each participant, I will schedule an interview with the selected participants at a location and time of their choosing.

2. I will meet each participant at the time and location they have chosen. After pressing the record button on my digital recording device, I will begin the interview by thanking each participant for choosing to volunteer his or her time for this study. Next, I will review the voluntary nature of their participation and option to quit participation at any time. I will ask the following open-ended questions and probing questions, as needed, to get adequate depth of interview data:

1. What marketing strategies have you used to sustain your business?

2. What marketing strategies worked best to retain current patients?

3. What marketing strategies worked best to gain new patients?

4. What are your current primary barriers to marketing?

5. How have you overcome these marketing barriers?

6. How have your marketing strategies evolved over the past 5 years?

7. How do you market your brand for sustainability?

8. How do you measure the effectiveness of your marketing strategies? 
9. What other information can you provide that we have not already discussed?

3. During the interview, I will record any pertinent observational details and researcher reflections in the following manner:

Date/Time:

Participant:

Location:

Details:

Reflections:

4. Upon completing the initial face-to-face interview, transcript review, and any follow up interviews, I will send the following thank-you letter to each participant:

Dear (Participant Name):

I wanted to take a moment to thank-you for participating in my research study on the marketing strategies that small physical therapy practice owners use to sustain their business. I acknowledge that you are a busy small business owner and your time is valuable. I appreciate your time and efforts throughout this process. I am currently analyzing the data and looking for themes. I will provide you with a complimentary copy of my study once completed. Please contact me if you have any questions. 
Sincerely,

Matthew Daugherty

Doctor of Business Administration Candidate

Walden University 
Appendix B: Confidentiality Agreement

\section{Name of Signer:}

During the course of my activity as professional transcriber for this research: Small Business Marketing Strategies for Physical Therapy Practice Owners. I will have access to information, which is confidential and should not be disclosed. I acknowledge that the information must remain confidential, and that improper disclosure of confidential information can be damaging to the participant.

\section{By signing this Confidentiality Agreement I acknowledge and agree that:}

1. I will not disclose or discuss any confidential information with others, including friends or family.

2. I will not in any way divulge, copy, release, sell, loan, alter or destroy any confidential information except as properly authorized.

3. I will not discuss confidential information where others can overhear the conversation. I understand that it is not acceptable to discuss confidential information even if the participant's name is not used.

4. I will not make any unauthorized transmissions, inquiries, modification or purging of confidential information.

5. I agree that my obligations under this agreement will continue after termination of the job that I will perform.

6. I understand that violation of this agreement will have legal implications.

7. I will only access or use systems or devices I'm officially authorized to access and I will not demonstrate the operation or function of systems or devices to unauthorized individuals.

Signing this document, I acknowledge that I have read the agreement and I agree to comply with all the terms and conditions stated above. 